\title{
A model of melt pond evolution on sea ice
}

\author{
Article
}

Published Version

Taylor, P. D. and Feltham, D. L. (2004) A model of melt pond evolution on sea ice. Journal of Geophysical Research, 109 (C12). C12007. ISSN 0148-0227 doi:

https://doi.org/10.1029/2004JC002361 Available at https://centaur.reading.ac.uk/35289/

It is advisable to refer to the publisher's version if you intend to cite from the work. See Guidance on citing.

Published version at: http://dx.doi.org/10.1029/2004JC002361

To link to this article DOI: http://dx.doi.org/10.1029/2004JC002361

Publisher: American Geophysical Union

All outputs in CentAUR are protected by Intellectual Property Rights law, including copyright law. Copyright and IPR is retained by the creators or other copyright holders. Terms and conditions for use of this material are defined in the End User Agreement.

\section{www.reading.ac.uk/centaur}

\section{CentAUR}

Central Archive at the University of Reading

Reading's research outputs online 


\title{
A model of melt pond evolution on sea ice
}

\author{
P. D. Taylor and D. L. Feltham \\ Centre for Polar Observation and Modelling, Department of Space and Climate Physics, University College London, \\ London, UK \\ Received 3 March 2004; revised 23 July 2004; accepted 1 October 2004; published 7 December 2004.
}

[1] A one-dimensional, thermodynamic, and radiative model of a melt pond on sea ice is presented that explicitly treats the melt pond as an extra phase. A two-stream radiation model, which allows albedo to be determined from bulk optical properties, and a parameterization of the summertime evolution of optical properties, is used. Heat transport within the sea ice is described using an equation describing heat transport in a mushy layer of a binary alloy (salt water). The model is tested by comparison of numerical simulations with SHEBA data and previous modeling. The presence of melt ponds on the sea ice surface is demonstrated to have a significant effect on the heat and mass balance.

Sensitivity tests indicate that the maximum melt pond depth is highly sensitive to optical parameters and drainage. INDEX TERMS: 4207 Oceanography: General: Arctic and Antarctic oceanography; 4255 Oceanography: General: Numerical modeling; 4299 Oceanography: General: General or miscellaneous; KEYWORDS: sea ice, melt pond, albedo, Arctic Ocean, radiation model, thermodynamic

Citation: Taylor, P. D., and D. L. Feltham (2004), A model of melt pond evolution on sea ice, J. Geophys. Res., 109, C12007, doi:10.1029/2004JC002361.

\section{Introduction}

[2] Sea ice is formed by the freezing of seawater in the high latitudes of the Northern and Southern Hemispheres and acts as a membrane between the atmosphere and the ocean, through which heat, moisture, and momentum are transported. It both influences and is influenced by the climate. Predictions from climate models indicate that increases in average temperature due to the enhanced greenhouse effect will be greatest in the Arctic [Cattle and Crossley, 1995]. Recent results from satellite observations have found a high correlation between melt season length and interannual variation of average sea ice thickness [Laxon et al., 2003].

[3] Melt ponds are the most distinctive summertime feature of Arctic sea ice, with estimated sea ice coverage ranging from 5 to $50 \%$ [Eicken et al., 1996]. Melt ponds are pools of water that collect on the surface of sea ice due to surface melt driven by increased short-wave radiation absorption in summer. This is in contrast to Antarctic sea ice, where melt ponds are relatively rare [Andreas and Ackley, 1982], except perhaps in the northwest Weddell Sea [Wadhams, 2000].

[4] Melt ponds influence the summertime energy and mass balance through the albedo-feedback mechanism [Ebert and Curry, 1993], alter the physical and optical properties of sea ice [Maykut, 1996; Perovich et al., 2002], can also affect the salt and heat budget of the ocean mixed layer [Eicken et al., 2002], and are an important factor influencing Arctic summertime ecology [Ferguson et al., 2000; Gradinger, 1996].

Copyright 2004 by the American Geophysical Union. 0148-0227/04/2004JC002361
[5] The albedo of pond-covered sea ice $(0.15-0.45$ [Fetterer and Untersteiner, 1998]) is less than bare sea ice and snow-covered sea ice $(0.52-0.87$ [Perovich, 1996]) and so pond-covered sea ice preferentially absorbs short-wave radiation. The difference in solar energy absorption between pond-covered and bare sea ice, combined with the natural and forced convection within the ponds, explains why the melt rate beneath melt ponds is 2-3 times that of bare sea ice [Bogorodskii, 1995; Fetterer and Untersteiner, 1998].

[6] Melt ponds influence salinity variation of sea ice and can drain, releasing relatively fresh water into the upper layers of the ocean. Drainage is believed to be the primary source of desalination of sea ice during summer [Cox and Weeks, 1974; Untersteiner, 1968], and fresh meltwater draining through sea ice can lead to the formation of under-ice melt ponds. Draining meltwater alters the energy and mass budget of the sea ice, and can alter the ocean heat flux [Notz et al., 2003].

[7] SHEBA (Surface HEat Budget of the Arctic Ocean) was an interdisciplinary sea ice field experiment to examine the processes that control feedback mechanisms such as the albedo-feedback mechanism and cloud-radiation feedback mechanism, and to develop improved models to improve simulations of the Arctic climate [Perovich et al., 1999]. The SHEBA camp drifted with the sea ice from fall 1997 to fall 1998, and meandered over $3000 \mathrm{~km}$ across the Arctic Ocean. In this paper, atmospheric data from SHEBA are utilized to force the model at its surface, and optical data from SHEBA are utilized to parameterize the optical properties of the model during the summer.

[8] Mellor and Kantha [1989] coupled a sea ice model to an ocean model and included a layer of standing water on 
the ice. The standing water layer acted as a store of latent heat and mass and did not influence the surface energy budget. The albedo of the sea ice was not affected by this layer of water. Although this model is only a partial description of melt ponds, it was shown that the sea ice model is sensitive to the additional mass stored at the surface, with $0.1 \mathrm{~m}$ of standing water leading to a $40 \%$ increase in the equilibrium ice thickness.

[9] Ebert and Curry [1993] proposed a sophisticated, one-dimensional thermodynamic model of sea ice that is an extension of Maykut and Untersteiner's [1971] thermodynamic model. Ebert and Curry's [1993] equation describing heat transport within the sea ice is identical to the equation used by Maykut and Untersteiner [1971], but they included a surface-dependent albedo, an explicit melt pond parameterization, and a lead parameterization. The melt pond parameterization is based on a simple energy balance based entirely on absorption of solar radiation in the pond and the surface of the sea ice.

[10] Ebert and Curry [1993] compared the melt pond component of their model to observations. The fractional area of melt ponds was an imposed function chosen to match a large data set; however, only limited data were available for comparison of the temporal evolution of melt pond depth [Ebert and Curry, 1993]. A limitation of the melt pond parameterization used in Ebert and Curry's [1993] model is that it does not consider the time dependency of the sensible heat stored within the melt ponds (and the effect of turbulent heat transport inside the pond) and the corresponding influence of melt ponds on the surface energy budget.

[11] In this paper a new one-dimensional, thermodynamic melt-pond-sea-ice model is developed. The meltpond-sea-ice model replaces the commonly used Beer's law representation of radiative transfer in sea ice with a two-stream radiation model. This model is advantageous in that the albedo can be calculated from the optical properties and ice thickness, whereas for Beer's law formulations, albedo is specified as an external parameter. In the presence of melt ponds, a parameterization is used to simulate the variation of optical properties caused by morphological changes to the sea ice during summer. The governing equation for temperature is based upon the equation describing conservation of heat in a mushy layer. Mushy layers describe binary alloys, and consist of a solid matrix surrounded by its melt. For sea ice the solid matrix is composed of effectively pure ice, and the melt is brine. The melt-pond-sea-ice model is primarily focused on Arctic sea ice, because the forcing data describe Arctic conditions; however, it is also applicable to melt ponds in the Antarctic. With some straightforward modifications, the model could also be applied to other geophysical surface melt processes such as surface melting of glaciers.

[12] In section 2, we describe the two-stream radiation model and the parameterization used to simulate summertime variation of optical properties. In section 3, we formulate the melt-pond-sea-ice model, describing heat transfer in each component of the model and the boundary conditions of the model. In section 4, the data used to force the model are outlined. In section 5, the seasonal evolution of the model is presented and the sensitivity of the model to candidate parameters is examined. Finally, section 6 summarizes the main conclusions.

\section{Radiation Model}

[13] Previous thermodynamic sea ice models have used Beer's law to describe radiative transfer within sea ice [e.g., Ebert and Curry, 1993; Maykut and Untersteiner, 1971]. The disadvantage of this is that the albedo is specified as an external parameter. Because melt pond formation is driven by the summertime increase in shortwave radiation, here we adopt a more sophisticated radiation model.

[14] In the presence of a snow cover, radiation is assumed to be attenuated so effectively at the surface of the snow that we neglect internal heating in the model. The total albedo has a constant wintertime value (0.84), and when the snow is melting the total albedo is linearly interpolated between the melting snow value (0.74) and that of the initial melt pond albedo calculated using the two-stream model.

[15] We use a three-layer, two-stream radiation model following Perovich [1990], where the layers correspond to the melt pond, underlying sea ice and (where it exists) a layer of refrozen sea ice on top of the melt pond. The twostream radiation model describes the radiation field in terms of an upwelling and downwelling stream. The advantage of this model is that albedo can be explicitly determined, although it suffers from the assumption that the incident radiation is diffuse and scattering is isotropic. However, during summer, there is a high percentage of cloud cover [Makshtas et al., 1998], so that the assumption of diffuse incident radiation is approximately valid [Perovich, 1990]. For computational convenience we do not use spectral variation or vertical variation of the optical properties in each layer, and we parameterize the optical properties in the presence of melt ponds to obtain more accurate summertime temporal variation of albedo. Using wavelength integrated properties should not significantly affect the qualitative results, since most of the radiative energy in the sea ice is absorbed near the surface and this can be well represented using a single-band model [Taylor, 2003].

[16] For the three-layer, two-stream radiation model we denote the layer closest to the atmospheric surface (the refrozen melt pond surface) by the suffix 0 , the melt pond or internal melt layer by the suffix 1 , and the lower sea ice layer by the suffix 2 . The position $z_{i}$ within each layer is measured relative to the surface of that layer $(i=0,1,2)$. The equations describing the variation of downwelling $\left(F_{\downarrow i}\right)$ and upwelling $\left(F_{\uparrow i}\right)$ irradiance in layer $i$ in the two-stream model are given by

$$
\begin{gathered}
\frac{\partial F_{\downarrow i}}{\partial z_{i}}=-\left(k_{i}+r_{i}\right) F_{\downarrow i}+r_{i} F_{\uparrow_{i}} \\
\frac{\partial F_{\uparrow i}}{\partial z_{i}}=\left(k_{i}+r_{i}\right) F_{\uparrow i}-r_{i} F_{\downarrow_{i}},
\end{gathered}
$$

where $k_{i}$ is the absorption coefficient in layer $i$, and $r_{i}$ is the scattering coefficient. Equations (1) and (2) describe the change in the downwelling (upwelling) irradiance (first term) because of loss due to absorption and scattering of the 
downwelling (upwelling) stream (second and third terms) and gain due to scattering of the upwelling (downwelling) stream (fourth term).

[17] The general solution of (1) and (2) under the restriction that $r_{i} \neq 0$ is

$$
\begin{gathered}
F_{\downarrow i}=s_{i} A^{i} e^{\kappa_{i} z_{i}}+\frac{B^{i}}{s_{i}} e^{-\kappa_{i} z_{i}} \\
F_{\uparrow i}=A^{i} e^{\kappa_{i} z_{i}}+B^{i} e^{-\kappa_{i} z_{i}},
\end{gathered}
$$

where $s_{i}=\left(\kappa_{i}-k_{i}\right) /\left(\kappa_{i}+k_{i}\right)$ is a proxy for sea ice albedo in the limit of large thickness and no Fresnel reflection [cf. Grenfell and Maykut, 1977], $\kappa_{i}=k_{i}^{2}+$ $2 k_{i} r_{i}$ is the extinction coefficient, and $A^{i}$ and $B^{i}$ are optical coefficients dependent upon optical properties and thickness. For simplicity, the upper layer of sea ice (the refrozen melt pond surface) is assumed to have the same optical properties as the lower layer, so that $\kappa_{0}=\kappa_{2}$ and $s_{0}=s_{2}$.

[18] If $r_{i}=0$ then there is no scattering and the medium through which the radiation travels is purely absorbing. This has been shown to be a valid approximation for melt ponds with a depth less than $1 \mathrm{~m}$ [Podgorny and Grenfell, 1996]. In this purely absorbing case, $\kappa_{i}=k_{i}$ and the general solution takes the form

$$
\begin{aligned}
& F_{\downarrow i}=C^{i} e^{-\kappa_{i} z_{i}} \\
& F_{\uparrow i}=D^{i} e^{\kappa_{i} z_{i}},
\end{aligned}
$$

where $C^{i}$ and $D^{i}$ are optical coefficients dependent on optical properties and thickness.

[19] The boundary conditions that are used in the threelayer, two-stream radiation model are the same as those used by Perovich [1990]. The thickness of each layer is $H_{i}$, and the optical properties of each layer are expressed in terms of the two independent parameters, which are the extinction coefficients $\kappa_{i}$ and the parameters $s_{i}=\left(\kappa_{i}-k_{i}\right)$ / $\left(\kappa_{i}+k_{i}\right)$ in the ice layers $(i=0,2)$, and the extinction coefficient $\kappa_{1}$ in the pond layer $(i=1)$. At the atmosphereice interface, both the incident short-wave radiation and the upwelling irradiance $F_{\uparrow 0}\left(z_{0}=0\right)$ can have a Fresnel reflection component, $R_{0}$ [Perovich, 1990]. This occurs only at the surface due to the difference between the real part of the index of refraction of air and ice. Between the internal layers of ice and internal melt it is assumed that the difference in the real part of index of refraction is negligible. Also, across each layer boundary the upwelling and downwelling fluxes are assumed to be continuous, so that energy is conserved. At the ice-ocean interface it is assumed that there is no Fresnel reflection and there is no radiation scattered upward within the ocean, so that the upwelling irradiance is negligible. Therefore the boundary conditions appropriate to the three-layer, two-stream model are

$$
F_{\downarrow 0}\left(z_{0}=0\right)=\left(1-R_{0}\right) F_{S W}+R_{0} F_{\uparrow 0}\left(z_{0}=0\right),
$$

$$
\begin{gathered}
F_{\downarrow 0}\left(z_{0}=H_{0}\right)=F_{\downarrow 1}\left(z_{1}=0\right), \\
F_{\uparrow 0}\left(z_{0}=H_{0}\right)=F_{\uparrow 1}\left(z_{1}=0\right), \\
F_{\downarrow 1}\left(z_{1}=H_{1}\right)=F_{\downarrow 2}\left(z_{2}=0\right), \\
F_{\uparrow 1}\left(z_{1}=H_{1}\right)=F_{\uparrow 2}\left(z_{2}=0\right), \\
F_{\uparrow 2}\left(z_{2}=H_{2}\right)=0,
\end{gathered}
$$

where $F_{S W}$ is the incident irradiance, and the Fresnel reflection coefficient $R_{0}=0.05$ [Perovich, 1990]. The six optical coefficients of the three-layer model are determined by substituting the general solution for each layer (equations (3) to (6)) into the six boundary conditions (equations (7) to (12)).

[20] The net irradiance at a point inside the sea ice $F_{\text {net }(i)}\left(z_{i}\right)$ is simply the difference between the downwelling and the upwelling stream. The rate of energy absorbed per unit volume within the melt-pond-sea-ice model is given by $-\partial F_{n e t(i)}\left(z_{i}\right) / \partial z_{i}$.

[21] The spectral albedo $\alpha_{\lambda}$ for solar radiation at a specific wavelength $\lambda$ is determined by the energy that undergoes Fresnel reflection at the surface plus the energy scattered upward through the surface from within the sea ice. The total albedo $\alpha$ is the spectral albedo weighted with the incoming radiation at each wavelength. Since the model used in this paper neglects spectral variation, the total albedo is equal to the spectral albedo. In terms of the two-stream model, the total (and spectral) albedo is given by

$$
\alpha=R_{0}+\frac{\left(1-R_{0}\right) F_{\uparrow 0}\left(z_{0}=0\right)}{F_{S W}} .
$$

[22] As melt ponds develop on the surface of sea ice during summer, the underlying sea ice undergoes significant physical changes affecting the optical and physical properties [Maykut, 1996]. To allow variation of the sea ice optical properties during summer, a parameterization for the optical parameter $s_{2}$ in the presence of melt ponds is developed by comparing the two-stream model to field data from the SHEBA experiment.

[23] The major uncertainty in summertime albedos comes from the significant variations in the optical properties of the ice underlying melt ponds, with spectral albedos of ice underlying ponds estimated to range from 0.2 to 0.7 [Podgorny and Grenfell, 1996]. Furthermore, as summer progresses the increased brine volumes in the sea ice beneath ponds lowers the extinction coefficient [Grenfell and Maykut, 1977]. This variation must be taken into consideration when modeling the melt pond evolution; otherwise the energy partitioning between the ice and the pond will be incorrect. To this end, the parameterization of $s_{2}$ is based upon the pond depth and albedo data from SHEBA. 


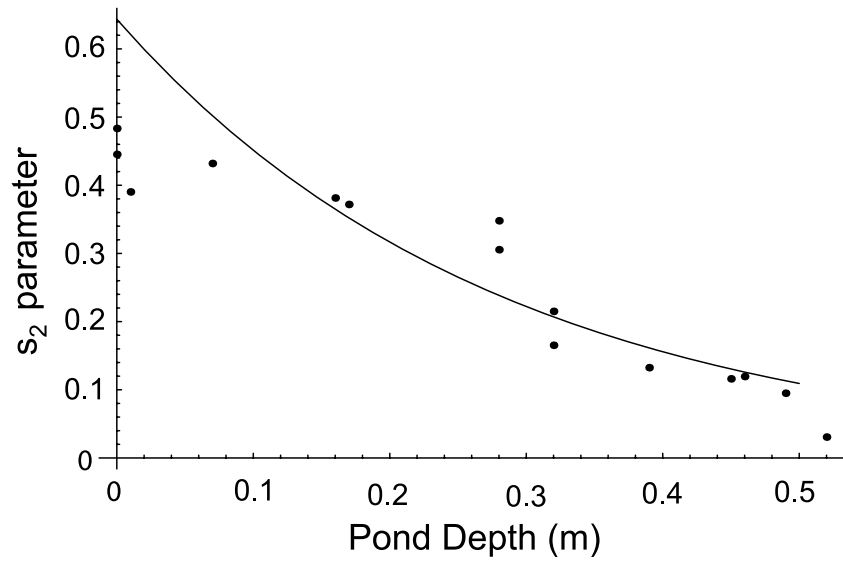

Figure 1. Comparison of optical parameter $s_{2}$ for sea ice using data (points) and parameterization with $\tau=3.55$ (line).

[24] It can be shown that for an infinitely thick sea ice layer without a melt pond, the one-layer, infinite-thickness, two-stream albedo $\alpha_{\infty}$ is given by

$$
\alpha_{\infty}=R_{0}+\frac{\left(1-R_{0}\right)^{2} s_{2}^{\text {winter }}}{1-R_{0} s_{2}^{\text {winter }}},
$$

where the parameter $s_{2}^{\text {winter }}$ is the constant value of the parameter $s_{2}$, used in the lower sea ice layer, when there is no melt pond. For sea ice thicker than $0.8 \mathrm{~m}$ the albedo does not vary significantly with thickness [Perovich et al., 1986], so that an appropriate value of the albedo at large thickness $\alpha_{\infty}$ can be used to determine $s_{2}^{\text {winter }}$ using equation (14). For an infinitely thick sea ice layer with a finite melt pond on its surface, the variable summertime value of $s_{2}$ can be derived in a similar way to the constant wintertime value $s_{2}^{\text {winter }}$ and is given by

$$
s_{2}=\frac{\alpha_{\infty}^{\text {pond }}-R_{0}}{\left(1-2 R_{0}+\alpha_{\infty}^{\text {pond }} R_{0}\right) \exp \left(-2 \kappa_{1} H_{1}\right)},
$$

where $\alpha_{\infty}^{\text {pond }}$ is the albedo of pond-covered, infinitely thick ice.

[25] The parameter $s_{2}$ can be calculated using equation (15) for a given melt pond depth $\left(H_{1}\right)$, melt pond albedo (assumed identical to $\alpha_{\infty}^{\text {pond }}$ ), and melt pond extinction coefficient $\left(\kappa_{1}\right)$. Melt pond depths and their corresponding total albedo can be obtained from SHEBA data available from Perovich et al. [1999], and the extinction coefficient of water can be estimated from existing data [e.g., Hale and Querry, 1973]. As the extinction coefficient decreases, $s_{2}$ decreases. There is also a correlation between pond depth and brine volume in sea ice beneath melt ponds, which can be deduced from the observation of increasing brine volume and average pond depths through the summer melt season [Fetterer and Untersteiner, 1998; Perovich et al., 1999]. Therefore it is assumed that the relationship between melt pond depth $H_{1}$ and $s_{2}$ is given by

$$
s_{2}\left(H_{1}\right)=s_{2}^{\text {winter }} \exp \left(-\tau H_{1}\right),
$$

for some parameter $\tau>0$. Although this relationship is arbitrary, it is reasonable since larger pond depths are associated with lower extinction coefficients within the sea ice (lower values of $s_{2}$ ), because of increased brine volume. Also, $s_{2}$ remains bounded above by its wintertime (pondfree) value and below by 0 , for all melt pond depths.

[26] The spectral albedo of melt ponds decay to their Fresnel reflection component for wavelengths greater than $700 \mathrm{~nm}$ [Grenfell and Maykut, 1977]. Therefore the bulk optical properties of the melt pond are chosen to be similar to spectral values for $\lambda$ less than $700 \mathrm{~nm}$. We used the 500-nm value of extinction as derived by Hale and Querry [1973], so that $\kappa_{1}=0.025 \mathrm{~m}^{-1}$. The infinite ice albedo is assumed to be 0.65 , corresponding to summertime melting white ice values [Perovich, 1996], so that $s_{2}^{\text {winter }}=0.643$. By minimizing the square of the difference between the values of $s_{2}$ derived from data using equation (15) and the values of $s_{2}$ determined from equation (16), the optimal parameter $\tau$ is found to be 3.55 (see Figure 1). The absorption coefficients $k_{i}$, in the sea ice layers of the radiation model, are determined using the definition of $s_{2}$ so that

$$
k_{2}=\kappa_{2} \frac{1-s_{2}}{1+s_{2}},
$$

where $\kappa_{2}=1.5 \mathrm{~m}^{-1}$ is assumed constant, and when there is no melt pond (but possibly an internal melt region) $s_{2}=$ $s_{2}^{\text {winter }}$.

\section{Model Description}

[27] The melt-pond-sea-ice model describes sea ice that becomes covered by melt ponds during the summer melt season. The model is one-dimensional and does not incorporate any horizontal parameterizations (e.g., meltwater runoff, ice divergence). There are five possible model configurations: (1) sea ice only; (2) sea ice and snow layer; (3) sea ice and melt pond; (4) sea ice, internal melt region, and refrozen upper ice layer; and (5) sea ice, internal melt region, refrozen upper ice layer, and snow layer. In winter, snow covers the sea ice.

[28] The standard annual cycle is shown schematically in Figure 2. Also shown are the equation numbers of the governing equations that describe heat transport within the ice, snow, and melt regions, and the equation numbers of the boundary conditions at the interfaces. The positions of the interfaces are measured with respect to the location of the snow-ice interface at the initial time (1 January). Heat transport in the sea ice and snow is governed by the mushy layer heat equation (17) and a simple diffusion equation (27), respectively. Snow fall occurs in a prescribed manner identical to that chosen by Maykut and Untersteiner [1971]. Melting snow in summer leads to initial melt pond formation. Melt ponds transport heat by diffusion or turbulent convection depending on the time-dependent Rayleigh number [Taylor, 2003]. At the end of summer, the melt pond refreezes from its upper surface down and for simplicity it is assumed that the refrozen pond forms sea ice of the same bulk salinity as the rest of the sea ice. Snow begins to fall in the fall, and so the model can consist of snowcovered refreezing ponds. Eventually the ponds completely refreeze and the model becomes snow-covered sea ice 


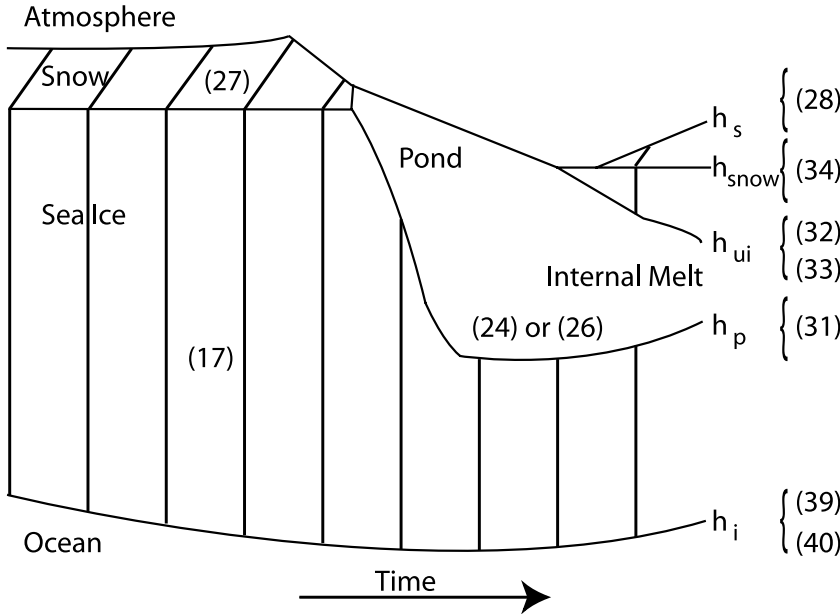

Figure 2. Schematic diagram of evolution of boundaries of melt-pond-sea-ice model. Equation numbers of governing equations and boundary conditions also shown.

again. Various other situations can occur depending on the physical parameters. For example, rapid drainage can prevent melt ponds forming, and in this case the model assumes that all additional surface meltwater instantaneously runs off (akin to previous thermodynamic models).

\subsection{Heat Transport Within Sea Ice}

[29] The most abundant salt in seawater is sodium chloride, although seawater also contains small amounts of other salts such as mirabilite and hydrohalite [Weeks and Ackley, 1986]. The sodium-chloride-water solution is the binary component alloy most similar to seawater [Weeks and Ackley, 1986; Wettlaufer et al., 1997]. Wettlaufer et al. [1997] found negligible differences between the structure of sea ice grown from seawater and ice grown from aqueous solutions of sodium chloride. Maykut and Light [1995] also found that radiatively, at temperatures above $-8.2^{\circ} \mathrm{C}$, there is little difference between sea ice formed from seawater and ice formed from sodium-chloride-water solution. Therefore we assume that seawater can be approximated by the binary alloy, sodium-chloride-water solution, at a salt concentration of $35 \mathrm{ppt}$ and that sea ice is well represented by the mushy layer formed from sodium chloride solution. A sea ice mushy layer consists of a solid ice matrix, consisting of almost pure ice, surrounded by its melt, which is brine. The vertical heat transport within the sea ice can be described by the one-dimensional equation describing conservation of heat in a mushy layer,

$$
(\rho c)_{m} \frac{\partial T}{\partial t}+(\rho c)_{l} U \frac{\partial T}{\partial z}=\frac{\partial}{\partial z}\left(k_{m} \frac{\partial T}{\partial z}\right)+\rho_{s} \mathcal{L} \frac{\partial \phi}{\partial t}-\frac{\partial}{\partial z} F_{n e t}(z),
$$

where $(\rho c)_{m}$ is the volumetric specific heat capacity of the sea ice, $T$ is the temperature within the sea ice, $t$ is time, $(\rho c)_{l}=4.185 \times 10^{6} \mathrm{~J} /\left(\mathrm{m}^{3} \mathrm{~K}\right)$ is the volumetric specific heat capacity of the liquid phase (brine), $U$ is the vertical Darcy velocity of brine flow within the sea ice, $z$ is the vertical spatial coordinate (pointing downward), $k_{m}$ is the thermal conductivity of the mushy layer, $\rho_{s} \mathcal{L}=3.0132 \times 10^{8} \mathrm{~J} / \mathrm{m}^{3}$ is the volumetric latent heat of fusion of the solid phase (fresh ice), $\phi$ is the solid fraction (the local volume fraction of sea ice that is solid), and $F_{n e t}(z)$ is the irradiance at depth $z$. Equation (17) describes the rate of change of heat in a control volume at fixed position due to advection of heat (second term), thermal diffusion (third term), latent heat released or absorbed due to internal phase change (fourth term), and radiative heating (fifth term).

[30] Following Wettlaufer et al. [2000], it is assumed that the volumetric specific heat capacity of the sea ice $(\rho c)_{m}$ and the thermal conductivity of the sea ice $k_{m}$ are determined by the mixture relations

$$
\begin{gathered}
(\rho c)_{m}=(\rho c)_{s} \phi+(\rho c)_{l}(1-\phi) \\
k_{m}=k_{s} \phi+k_{l}(1-\phi),
\end{gathered}
$$

where $(\rho c)_{s}=1.883 \times 10^{6} \mathrm{~J} /\left(\mathrm{m}^{3} \mathrm{~K}\right)$ is the volumetric specific heat capacity of the solid phase, $k_{s}=2 \mathrm{~W} /(\mathrm{m} \mathrm{K})$ is the thermal conductivity of the solid phase, and $k_{l}=$ $0.5 \mathrm{~W} /(\mathrm{m} \mathrm{K})$ is the thermal conductivity of the liquid phase, which are all assumed constant. For simplicity the solid and liquid densities are assumed identical $\left(\rho_{s}=\rho_{l}\right)$, so that dynamic effects due to volumetric changes during phase change can be ignored.

[31] The sea ice is assumed to be in local thermodynamic equilibrium. For local thermodynamic equilibrium to be maintained, the solute must diffuse much faster than the diffusion of variations in sensible and latent heat fluxes through the mushy layer depth. If $\delta$ is the dendrite (platelet) spacing, then the interstitial solute transport timescale is $\delta^{2} / D_{l}$, where $D_{l}$ is the diffusivity of salt in the brine. Therefore, to maintain local thermodynamic equilibrium, $\delta^{2} / D_{l}$ is required to be much less than the timescale of heat transport through the mushy layer [Feltham and Worster, 2000]. In sea ice the interstitial solute transport timescale is about $1000 \mathrm{~s}$, which is less than the typical timescale of thermodynamic variations in sea ice such as diurnal forcing [Feltham and Worster, 2000]. When sea ice is in local thermodynamic equilibrium, it can be assumed that the temperature and brine concentration lie on the liquidus curve in the phase equilibrium diagram for seawater. Close to the freezing temperature of pure water the liquidus curve is linear, and it is assumed that this relationship is valid for all temperatures, so that

$$
T=T_{L}(C)=-\Gamma C+T_{L}(0),
$$

where $T_{L}(C)$ is the equilibrium freezing temperature of a sodium-chloride-water solution at a concentration $C, T_{L}(0)$ is the equilibrium freezing temperature at zero concentration, and $\Gamma=0.0514 \mathrm{~K} / \mathrm{ppt}$ is the gradient of the linearized liquidus curve.

[32] The local bulk salinity is defined to be

$$
C_{\text {bulk }}(z)=\phi C_{s}+(1-\phi) C,
$$

which is the local concentration of salt per unit volume of sea ice, and $C_{s}$ is the concentration of solute in the solid phase, which is effectively zero [Weeks and Ackley, 1986]. It is assumed that the local bulk salinity through the depth of 
the sea ice is a constant $3.2 \mathrm{ppt}$ [Ebert and Curry, 1993] and remains so throughout simulations. The value of $3.2 \mathrm{ppt}$ for the constant bulk salinity is consistent with the bulk salinity of multiyear sea ice of about $2 \mathrm{~m}$ thickness [Kovacs, 1996]. The assumption of constant local bulk salinity allows the solid fraction to be expressed in terms of temperature by rearranging equation (21) and using the liquidus relationship (20). Therefore the temperature determines the local solid fraction and hence the thermal conductivity and specific heat capacity. When there is a melt pond, the solid fraction near the surface of the sea ice is always small, so that the thermal properties are close to those of the liquid component. At the base of the sea ice the solid fraction is always large, so that the thermal properties are close to those of the solid component. Therefore, altering the bulk salinity will not affect the melt rates significantly. Replacing the time derivative of the solid fraction in equation (17) and replacing the solid fraction in the mixture relations (18) and (19) transforms equation (17) into a nonlinear advectiondiffusion equation, which is analogous to that used by Maykut and Untersteiner [1971] when there is no advection.

\subsection{Heat Transport Within Melt Pond and Internal Melt Region}

[33] For melt ponds with low salinities, where the surface is being heated, "warm" surface water will be more dense than cool water at the base of the melt pond, and so there will be a natural propensity for the surface water to sink and be replaced by water at depth. This overturning is inhibited by frictional losses due to the melt pond's viscosity and heat diffusion away from a sinking plume, which reduces its negative buoyancy. Turbulent convective motions take place when the melt pond becomes dynamically unstable, which occurs once the time-dependent Rayleigh number $\mathrm{Ra}(t)$ exceeds the critical Rayleigh number $\mathrm{Ra}_{\text {crit. }}$ The timedependent Rayleigh number is given by

$$
\operatorname{Ra}(t)=\frac{g \alpha^{*} \Delta T H_{1}^{3}}{\nu_{l} \kappa_{l}},
$$

where $g=9.81 \mathrm{~m} / \mathrm{s}^{2}$ is the magnitude of acceleration due to gravity, $\alpha^{*}=5 \times 10^{-5} \mathrm{~K}^{-1}$ is the coefficient of thermal expansion of the water in the melt pond, $\Delta T$ is the temperature difference across the pond, $\kappa_{l}=k_{l} /(\rho c)_{l} \simeq$ $1.19 \times 10^{-7} \mathrm{~m}^{2} / \mathrm{s}$ is the thermal diffusivity of the melt pond, $\nu_{l}=10^{-6} \mathrm{~m}^{2} / \mathrm{s}$ is the kinematic viscosity of the water in the melt pond, and $H_{1}$ is the depth of the melt pond (following the notation used in section 2). The critical Rayleigh number $\mathrm{Ra}_{\text {crit }}=630$ is assumed to be constant from a numerical study [Taylor, 2003].

[34] A simple order of magnitude estimate of the Rayleigh number of a $0.1-\mathrm{m}$ melt pond assuming a $0.2 \mathrm{~K}$ temperature difference across the entire pond depth is

$$
\operatorname{Ra}(t) \simeq \frac{10 \mathrm{~m} / \mathrm{s}^{2} \cdot 5 \times 10^{-5} \mathrm{~K}^{-1} \cdot 0.2 \mathrm{~K} \cdot(0.1 \mathrm{~m})^{3}}{10^{-6} \mathrm{~m}^{2} / \mathrm{s} \cdot 10^{-7} \mathrm{~m}^{2} / \mathrm{s}} \simeq 10^{6},
$$

using equation (22). Such large Rayleigh numbers lead to turbulent convective motion.

[35] Observations show that as well as natural convection, there can be forced convection within the pond driven by the wind [Eicken et al., 2002]. Observations of scalping at the sides of melt ponds [Fetterer and Untersteiner, 1998] have been explained by melt pond surface currents. The rate of turbulent heat transfer through the pond may be increased in the presence of wind-driven mixing; however, as the sensible and latent heat losses to the atmosphere may be affected, the impact on the melt rate beneath the melt pond is not clear.

[36] In the nonturbulent regime $\left(\operatorname{Ra}(t)<\mathrm{Ra}_{\text {crit }}\right)$, the equation describing conservation of heat is

$$
(\rho c)_{l}\left(\frac{\partial T}{\partial t}+u \frac{\partial T}{\partial z}\right)=k_{l} \frac{\partial^{2} T}{\partial z^{2}}-\frac{\partial}{\partial z} F_{\text {net }}(z),
$$

where $u$ is the fluid velocity in the liquid region. Since the model is one-dimensional, the assumption of continuity of mass flux at the lower boundary of the liquid region implies that $u=U$. Equation (24) describes the rate of change of temperature in a control volume at fixed position (first term), subject to advection of heat (second term), thermal diffusion (third term), and radiative heating (fourth term).

[37] Turbulent convection leads to mixing of the melt pond, except near the boundaries where diffusive effects are dominant. As the Rayleigh number becomes larger the temperature gradient steepens near the boundaries and flattens in the core of the melt pond. In the turbulent case, it is assumed that the pond interior is well mixed and the evolution of the mean core temperature of the pond $\bar{T}(t)$ is to be determined. For simplicity, the pond salinity $C_{\text {pond }}$ is assumed constant and the mixing of the pond is assumed to leave the salinity unchanged.

[38] Heat transfer across the melt-pond-sea-ice and internal-melt-sea-ice boundaries due to turbulent convective overturning is modeled using the four-thirds law for turbulent convection. The four-thirds law arises when the heat flux across a fluid layer is assumed to be independent of the depth of a fluid layer, so that the Nusselt number, which is the ratio of the convective to diffusive heat flux, is proportional to the Rayleigh number to the power of one third [Linden, 2000]. Then the heat flux at the boundary of a liquid region (melt pond or internal melt), directed outward, is given by

$$
\begin{aligned}
F_{c}\left(T^{*}\right) & =\operatorname{sgn}\left(\bar{T}-T^{*}\right)(\rho c)_{l} J\left|\bar{T}-T^{*}\right|^{4 / 3} \quad \text { if } \operatorname{Ra}(t) \geq \mathrm{Ra}_{\text {crit }} \\
& =-k_{l} \frac{\partial T}{\partial z} \quad \text { if } \operatorname{Ra}(t)<\operatorname{Ra}_{\text {crit }} \text { and } z=h_{l} \\
& =k_{l} \frac{\partial T}{\partial z} \quad \text { if } \operatorname{Ra}(t)<\operatorname{Ra}_{\text {crit }} \text { and } z=h_{u}
\end{aligned}
$$

where $T^{*}$ is the boundary temperature, $h_{l}$ is the location of the lower boundary of the liquid region (pond or internal melt), $h_{u}$ is the location of the upper boundary of the liquid region, and

$$
J=\gamma\left(\frac{g \alpha^{*} \kappa_{l}^{2}}{\nu_{l}}\right)^{1 / 3}
$$

where $\gamma$ is a dimensionless number taken to be 0.1 [Huppert, 2000]. 
[39] For the turbulent case, conservation of energy in the liquid region yields

$$
(\rho c)_{l} H_{1} \frac{\partial \bar{T}}{\partial t}=-F_{c}\left(T_{l}\right)-F_{c}\left(T_{u}\right)-\int_{h_{u}}^{h_{l}} \frac{\partial}{\partial z} F_{\text {net }}(z) \mathrm{d} z,
$$

where $T_{l}$ is the temperature at the lower boundary of the liquid region, and $T_{u}$ is the temperature at the upper boundary of the liquid region. It is assumed that the radiative energy that would be absorbed across the thin boundary layers is transferred instantaneously into the turbulent core, and that the boundary layers are always much thinner than the convecting region. This should be valid for developed melt ponds since $\mathrm{Ra}(t) / \mathrm{Ra}_{\text {crit }}$ is typically $\mathcal{O}\left(10^{3}\right)$ (using equation 23). Equation (26) equates the change in total sensible heat of the turbulent core (first term) to the heat flux in/out from the upper boundary (second term) minus the heat flux out of the lower boundary (third term) plus the total heat gain from internal heating due to incoming short-wave radiation (fourth term).

\subsection{Heat Transport Within Snow}

[40] Since the snow cover is highly complex and is not the main focus of this paper, we use the model of snow introduced by Maykut and Untersteiner [1971]. Heat transport within the snow is governed by the diffusion equation,

$$
\rho_{\text {snow }} c_{\text {snow }} \frac{\partial T}{\partial t}=k_{\text {snow }} \frac{\partial^{2} T}{\partial z^{2}},
$$

where $\rho_{\text {snow }}=330 \mathrm{~kg} / \mathrm{m}^{3}$ is the constant wintertime density of the snow, $c_{\text {snow }}=2092 \mathrm{~J} /(\mathrm{kg} \mathrm{K})$ is the constant volumetric specific heat capacity of snow, and $k_{\text {snow }}=$ $0.31 \mathrm{~W} /(\mathrm{m} \mathrm{K})$ is the constant thermal conductivity of snow. Radiation is neglected within the snow cover since most of the short-wave energy is scattered near the surface [Wiscombe and Warren, 1980]. This leads to high albedos (greater than 0.8 ), so that only a relatively small fraction of incident radiation penetrates the snow and leads to internal heating. The influence of this small amount of radiation should only influence the timing of the start of the melt season, and is unlikely to produce qualitatively different results during the melt season.

\subsection{Boundary Conditions}

[41] The net energy per unit area at the upper surface $(z=$ $h_{s}$ ), i.e., the interface with the atmosphere, for all surface types is given by

$\left(E_{\text {net }}\right)_{0}^{x} \equiv \chi^{x}+F_{L W}-\epsilon^{x} \sigma T_{0}^{4} !+\left(1-i_{0}^{x}\right)(1-\alpha) F_{S W}-F_{\text {sens }}^{x}-F_{\text {lat }}^{x}$,

where superscript $x$ denotes the surface type ( $m=$ sea ice, snow $=$ snow, $l=$ pond), $\chi^{x}$ is the conductive flux (sea ice, snow, or diffusive melt pond) or convective flux (convective melt pond) into the surface, $\epsilon^{x}$ is the emissivity $\left(\epsilon^{m}=\epsilon^{\text {snow }}=\right.$ $0.99, \epsilon^{l}=0.97$ [Ebert and Curry, 1993]), $\sigma=5.67 \times 10^{-8}$ is the Stefan-Boltzmann constant, $T_{0}(\mathrm{~K})$ is the temperature at the surface, and $i_{0}^{x}$ is the fraction of radiation that is not absorbed near the surface. For snow and sea ice, $\chi^{x}=k_{x} \partial T / \partial z$, and for a melt pond, $\chi^{l}=F_{c}\left(T_{0}\right)$, as given by equation (25).
[42] For the sensible and latent heat fluxes, we use bulk parameterizations identical to Ebert and Curry [1993], given by

$$
\begin{aligned}
& F_{\text {sens }}^{x}=\rho_{a} c_{a} C_{T}^{x} v\left(T_{a}-T_{0}\right) \\
& F_{\text {lat }}^{x}=\rho_{a} \mathcal{L}^{*} C_{T}^{x} v\left(q_{a}-q_{0}\right),
\end{aligned}
$$

where $\rho_{a}=1.275 \mathrm{~kg} / \mathrm{m}^{3}$ is the density of dry air, $c_{a}=1005 \mathrm{~J} /$ $(\mathrm{kg} \mathrm{K})$ is the specific heat capacity of dry air, $T_{a}(\mathrm{~K})$ is the air temperature at some reference height (obtained from data), $v(\mathrm{~m} / \mathrm{s})$ is the wind speed at the reference height (obtained from data), $\mathcal{L}^{*}=2.501 \times 10^{6} \mathrm{~J} / \mathrm{kg}$ is the latent heat of vaporization, $q_{0}$ is the specific humidity (mass of water vapor per unit mass of air) at the surface, $q_{a}$ is the specific humidity at the reference level (obtained from data), and $C_{T}^{x}$ is a stability dependent bulk transfer coefficient following Ebert and Curry [1993]. Since there have not been any measurements of sensible or latent heat fluxes over melt ponds to date (E. L. Andreas, personal communication, 2002), we assume that the value of the transfer coefficient $C_{T}^{l}$ for melt ponds is identical to that used for leads by Ebert and Curry [1993]. The specific humidity at the surface is estimated using the assumption that the air at the surface is saturated, so that

$$
q_{0}=\frac{0.622 p_{v}}{p_{\text {atm }}-0.378 p_{v}},
$$

where $p_{v}=2.53 \times 10^{8} \exp \left(-5420 / T_{0}\right)(\mathrm{kPa})$ is the partial pressure of water vapor [Rogers and Yau, 1989], and $p_{\text {atm }}(\mathrm{kPa})$ is the atmospheric pressure (obtained from data).

[43] The parameter $i_{0}^{x}$ represents the fraction of incident radiation that passes through the surface into the interior of the ice, pond, or snow, and does not contribute to energy changes at the surface. While $i_{0}^{x}$ will vary on a short timescale due to cloudiness, we neglect this variation in our study. The surface energy fluxes (e.g., long-wave radiation, and turbulent fluxes) are transferred over small lengthscales (e.g., absorption depth, viscous molecular sublayer). Therefore the $i_{0}^{x}$ parameter can be interpreted physically as the fraction of incident short-wave radiation that is not absorbed over a small lengthscale at the surface. To conserve energy within the body of the melt-pond-seaice system, the radiation predicted by the two-stream radiation model is attenuated by $i_{0}^{x}$ of its initial value. Clearly, from the assumption that no radiation penetrates snow-covered sea ice, we have $i_{0}^{\text {snow }}=0$. In a numerical simulation, energy is only "measured" at the location of grid points. Therefore $i_{0}^{x}$ must represent the fraction of energy that passes through the surface of the model to the first interior grid point. The extinction coefficient decreases by up to 2 orders of magnitude near the surface of sea ice [Grenfell and Maykut, 1977], so that unless the optical model used reproduces the correct variation between the first two grid points, the error introduced must be accounted for by modifying the magnitude of $i_{0}^{m}$. The radiation model that we use neglects spectral variation, and longer wavelengths of radiation are absorbed more effectively than shorter wavelengths. 
[44] Previous studies [e.g., Ebert and Curry, 1993; Maykut and Untersteiner, 1971] had relatively coarse resolutions; however, in the melt-pond-sea-ice model calculations presented here, we have used a fixed number of grid points at a much higher resolution (641 grid points), and our model does not have spectral variation or vertical variations of optical properties within each layer (ice/pond). Therefore, for the sea ice surface, we define $i_{0}^{m}$ as the minimum of 0.4 and the ratio of the net irradiance at the first interior grid point to the irradiance at the surface, which is the fraction of incident radiation that is not reflected by the sea ice at the first interior grid point. This ensures that subsurface melting for the case of melting bare sea ice is avoided [Taylor, 2003]. This is necessary because the radiation model is insufficient to describe the variation in optical properties near the surface of the sea ice in this case. For melt ponds, most of the short-wave radiation beyond $700 \mathrm{~nm}$ is absorbed very effectively [Perovich et al., 1999]. The rapidly absorbed radiation is assumed to contribute to the surface energy balance via the $i_{0}^{l}$ parameter. From observations of cloudy sky incident radiation [Grenfell, 1979], up to $40 \%$ of the incident short-wave radiation field is beyond the $700 \mathrm{~nm}$ range. Therefore the parameter $i_{0}^{l}$ is assumed constant and is set equal to 0.6 .

[45] For numerical simplicity, we assume that the melting temperature of the upper surface of the sea ice $\left(T_{L}\left(C_{\text {pond }}\right)=\right.$ $-0.2^{\circ} \mathrm{C}$ ) is constant and is marginally less than the equilibrium freezing temperature of the bulk salinity of the ice $\left(T_{L}\left(C_{\text {bulk }}\right)\right)$, so that an explicit Stefan condition can be used. This is an assumption made for numerical convenience. In the (typical) case that the pond salinity is less than the bulk salinity of the sea ice, the solid fraction $\phi$ at the pond-ice interface is zero and the interface position must be determined implicitly from the balance of energy flux across the interface. Setting the solid fraction to be a small constant enables the interface position to be determined explicitly and is justified through our numerical experiments and previous calculations [e.g., Feltham and Worster, 1999]. If the surface temperature is less than the melting temperature, then the net energy at the upper surface of the sea ice $\left(E_{\text {net }}\right)_{0}^{m}$ must be zero. If the surface temperature is at the melting temperature, then the net energy at the surface must balance the latent heat required to melt the mushy layer, $\rho_{s} \mathcal{L} \phi d h_{s} / d t$.

[46] If a melt pond forms, then the surface energy balance for the melt pond $\left(E_{\text {net }}\right)_{0}^{l}$ is used and must equal zero. The velocity of the pond-ice boundary is determined from the Stefan condition,

$$
\rho_{s} \mathcal{L} \phi \frac{d h_{p}}{d t}=k_{m} \frac{\partial T}{\partial z}+F_{c}\left(T_{L}\left(C_{\mathrm{pond}}\right)\right), \quad\left(z=h_{p}\right)
$$

[47] We assume that the refreezing surface of a melt pond forms a mushy layer of the same constant bulk salinity as the lower sea ice layer, and with freezing temperature identical to the upper surface of the lower sea ice layer. This enables the sea ice to reform as a continuous block once the internal melt region has completely refrozen. At the upper-ice-internal-melt interface $\left(z=h_{\text {ui }}\right)$ the temperature is at the melting temperature of the pond, so that

$$
T=T_{L}\left(C_{\text {pond }}\right),
$$

and the velocity of the boundary is given by the Stefan condition

$$
\rho_{s} \mathcal{L} \phi \frac{d h_{\mathrm{ui}}}{d t}=k_{m} \frac{\partial T}{\partial z}-F_{c}\left(T_{L}\left(C_{\mathrm{pond}}\right)\right) .
$$

[48] The accretion of snow onto the ice surface in the model is identical to the findings of Maykut and Untersteiner [1971] and accumulates linearly at different rates during winter. An accumulation of $30 \mathrm{~cm}$ of snow occurs between 20 August and 30 October. An additional $5 \mathrm{~cm}$ of snow falls from 1 November to 30 April. Finally, $5 \mathrm{~cm}$ falls from 1 May to 31 May, so that in total, there is $40 \mathrm{~cm}$ of snowfall per year. Qualitatively, this is similar to the results from SHEBA [Perovich et al., 1999], although at SHEBA the initial accumulation was less rapid than in this case. At the snow-ice interface $\left(z=h_{\text {snow }}\right)$ it is assumed that there is no melting until a melt pond forms. When there is no melting at the snow-atmosphere interface the heat flux is assumed to be continuous across the snow-ice boundary, and so

$$
k_{\text {snow }} \frac{\partial T}{\partial z}=k_{m} \frac{\partial T}{\partial z} .
$$

It is also assumed that when there is no melting the temperature is continuous across the snow-ice interface. The evolution of the snow-ice interfacial temperature is determined implicitly from equation (34) using an iterative method.

[49] If the surface temperature of the snow is less than its melting temperature $(273 \mathrm{~K})$, then the net energy at the surface $\left(E_{\text {net }}\right)_{0}^{\text {snow }}$ must be zero. The melting of snow is complex, with meltwater percolation and refreezing, and rapid densification of the snow cover [Maykut and Untersteiner, 1969]. Since the primary interest here is in the role of melt ponds, we utilize a similar methodology to Maykut and Untersteiner [1971]. As soon as the surface temperature of the snow reaches the melting point, the snow is allowed to melt. There is an initial amount of melt as the snow layer becomes isothermal at its melting point (see below). Subsequently, further melt is determined by the requirement that the net energy at the surface must balance the latent heat required to melt the snow layer, so that

$$
\rho_{\text {snow }} \mathcal{L}_{\text {snow }} \frac{d h_{\text {snow }}}{d t}=\left(E_{\text {net }}\right)_{0}^{\text {snow }},
$$

where $\mathcal{L}_{\text {snow }}=332424 \mathrm{~J} / \mathrm{kg}$ [Ebert and Curry, 1993] is the constant latent heat of the snow, and $\rho_{\text {snow }}$ is the variable density of snow (see below).

[50] The initial quantity of melting is determined by equating the energy required to make the snow layer isothermal at its melting temperature and to raise the surface of the sea ice to its melting temperature (between the first two grid points) with the latent heat required to melt the undetermined quantity of snow. At this time, the temperature profiles within the snow and between the first two grid points within the sea ice are approximately linear.

[51] Since the number of grid points is large, the energy required to raise the sea ice surface to its melting temperature is negligible compared to the energy required to make 
the snow layer isothermal. Therefore, assuming the temperature profile in the snow is linear, the amount of melting at the surface can be approximated by

$$
\left(h_{s}^{*}-h_{s}\right)=\frac{c_{\text {snow }}\left(h_{\text {snow }}-h_{s}\right)\left(T_{0}-T_{\text {ice }}^{*}\right)}{2 \mathcal{L}_{\text {snow }}},
$$

where $z=h_{s}\left(z=h_{s}^{*}\right)$ is the location of the surface of the snow layer before (after) melting has occurred, and $T_{\text {ice }}^{*}$ is the temperature of the snow-ice interface before melting has occurred.

[52] Once this quantity of melting has occurred the snow is assumed instantaneously to be isothermal at its melting temperature and the ice surface is brought to its melting temperature. The density of the snow is also assumed to increase instantaneously to a limiting value, so that $\rho_{\text {snow }}$ increases to $450 \mathrm{~kg} / \mathrm{m}^{3}$ [Maykut and Untersteiner, 1971], to represent rapid densification. The snow is then allowed to melt according to equation (35) until a melt pond forms, with the initial depth of the melt pond being given by $\left(h_{\text {snow }}\right.$ $\left.-h_{s}^{*}\right) \rho_{\text {snow }} / \rho_{l}$. For simplicity, we assume that once the depth of the snow surface melts to the initial pond height the melting snow becomes a melt pond.

[53] Unlike previous models, it is required that the snow melts and initiates the formation of a melt pond. Therefore, conservation of mass and energy must be used to estimate the variation of density of the snow as it initially melts to form a melt pond. A linear variation of density with snow depth $H_{\text {snow }}(t)$ does not satisfy conservation of energy. Therefore we assume that the variation of density with snow depth varies quadratically according to

$$
\rho_{\text {snow }}\left(H_{\text {snow }}(t)\right)=a H_{\text {snow }}(t)^{2}+b H_{\text {snow }}(t)+c,
$$

where $a, b$, and $c$ are constants determined by the conditions that the initial density of the snow is $\rho_{\text {snow }}\left(H_{\text {snow }}\left(t_{0}\right)\right)=$ $450 \mathrm{~kg} / \mathrm{m}^{3}$ at time $t_{0}$, and the final density of the snow, once it has formed a melt pond, is $\rho_{\text {snow }}\left(H_{\text {snow }}\left(t_{1}\right)\right)=1000 \mathrm{~kg} / \mathrm{m}^{3}$ at time $t_{1}$, where $H_{\text {snow }}\left(t_{1}\right)$ is the water equivalent of the initial snow layer after initial melting, and the total energy required to melt the snow satisfies

$$
\begin{gathered}
\int_{t_{0}}^{t_{1}} \rho_{\text {snow }}\left(H_{\text {snow }}(t)\right) \mathcal{L}_{\text {snow }} \frac{d H_{\text {snow }}(t)}{d t} d t \\
=-\rho\left(H_{\text {snow }}\left(t_{0}\right)\right) \mathcal{L}_{\text {snow }} H_{\text {snow }}\left(t_{0}\right) .
\end{gathered}
$$

The exact densification process is unimportant to the simulation of melt ponds. However, it is necessary to ensure that the model initiates with a melt pond from the melting of snow, and also that the model conserves energy.

[54] Since the melt-pond-sea-ice model does not contain any description of the mixed layer of the ocean, we assume, in common with previous models [e.g., Bitz and Lipscomb, 1999; Ebert and Curry, 1993], that the ocean has constant salinity (35 ppt) and is at its equilibrium freezing temperature. Then, any surplus or deficit of salt due to phase change at the sea-ice-ocean interface is assumed to be instantly removed to the mixed layer of the ocean. At the sea-ice-ocean interface $z=h_{i}$, the sea ice is at the freezing temperature of the ocean, so that

$$
T=T_{L}\left(C_{\text {ocean }}\right)
$$

The velocity of the ice-ocean boundary is given by the Stefan condition,

$$
\rho_{s} \mathcal{L} \phi \frac{d h_{i}}{d t}=k_{m} \frac{\partial T}{\partial z}-F_{\text {ocean }}, \quad\left(z=h_{i}\right)
$$

where $F_{\text {ocean }}$ is the heat flux from the ocean directed into the base of the ice. Equation (40) states that the excess/deficit of heat at the melting interface balances the latent heat released/absorbed at the melting interface.

\subsection{Drainage}

[55] Since summer sea ice is porous [Eicken et al., 2002], drainage occurs within melt ponds that are above sea level at a rate dictated by the pressure head that they create. This is believed to be the primary source of desalination (flushing) of multiyear sea ice [Cox and Weeks, 1974; Untersteiner, 1968].

[56] Vertical drainage through sea ice occurs relatively rapidly, so that the position of the surface of a melt pond relative to the sea surface is essentially dependent on the relative area of the melt pond to its catchment area from which surface melt runs into the pond. For reasonably large ponds the net result is that their surfaces become fixed at the sea surface [Perovich et al., 2003; Taylor, 2003], so that the effective drainage rate is then approximately equal to changes in freeboard.

[57] The net upward motion of sea ice floes which melt during summer has an approximately constant rate [Perovich et al., 1999], which we take to suggest that the effective sea level melt-pond drainage rate is also constant. From these data, we assume that the effective drainage rate $\left(d h_{s} / d t\right)$ is a constant $1.75 \mathrm{~cm} /$ day.

\subsection{Method of Solution}

[58] The sets of equations to be solved within each domain are decoupled, in the sense that the interfacial temperatures at the boundaries are fixed, except when a snow layer is present that is not melting.

[59] The governing equations and boundary conditions were nondimensionalized. The governing equations for each layer (snow layer, upper ice layer, melt pond/internal melt, lower ice layer) were transformed from the $(z, t)$ coordinate system to the $(\xi, \zeta)$ coordinate system, by the transformation

$$
\xi=\frac{z-h_{a}}{h_{b}-h_{a}}, \quad \zeta=t
$$

where $h_{a}<h_{b}$ are the positions of the boundaries of the respective layers. The moving domain $\left[h_{a}, h_{b}\right]$ is thus transformed onto the fixed domain $[0,1]$. A major advantage of this method is that interpolation of temperatures at the moving boundaries is not required, and that the number of grid points in the numerical scheme remains fixed. A further advantage of this method is that library routine D03PCF from the Numerical Algorithms Group can be used to solve the governing equations. 


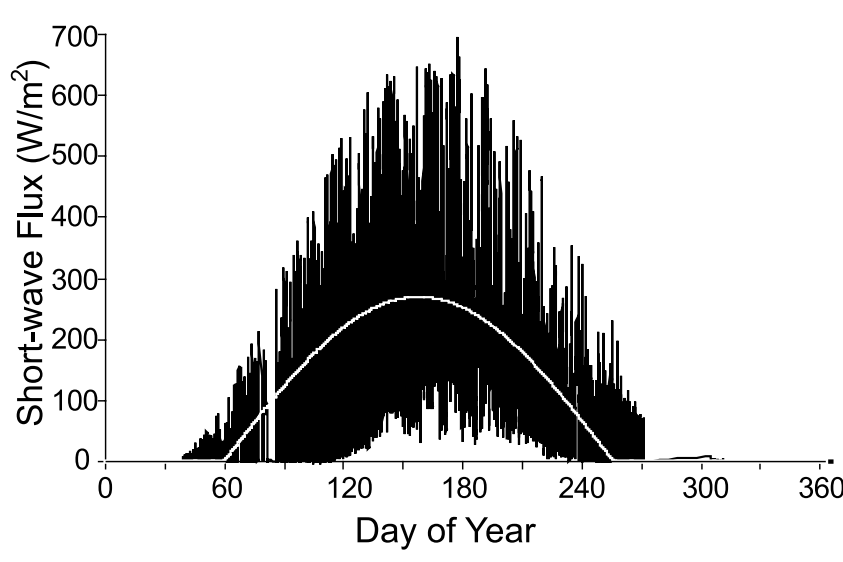

Figure 3. Fitted (white line) and observed (black) seasonal evolution of short-wave radiation $\left(F_{\mathrm{SW}}\right)$. (Day 0 denotes 1 January 1998. Data after day 300 correspond to fall 1997 measurements.)

[60] To solve the coupled snow-ice layer equations using D03PCF an iterative scheme was used to calculate the correct interfacial temperature at the end of each time step. The temperature gradients at each side of the interface were approximated using a three-point backward (snow)/forward (ice) difference approximation. D03PCF is integrated using an initial estimate of the interfacial temperature at the end of the time step. The estimate is calculated from the current rate of change of the interfacial temperature determined from previous time steps. The interfacial condition on the heat flux (equation (34)) forms a quadratic equation for the interfacial temperature. The expected interfacial temperature at the end of the time step is calculated from this quadratic expression once D03PCF has been integrated forward in time. If the difference between the initial estimate and the expected interfacial temperature is greater than a prescribed tolerance $(0.001$, in nondimensional temperature units), then the expected interfacial temperature is used as the initial estimate in the next iteration of D03PCF. If the difference is less than the prescribed tolerance, then the iterations are stopped.

[61] During each time step, the forcing fluxes $\left(F_{S W}, F_{L W}\right.$, $F_{\text {sens }}^{x}, F_{\text {lat }}^{x}$, and $\left.F_{\text {ocean }}\right)$ and the thickness of each layer are assumed fixed. Once the temperature becomes greater than the melting temperature upon integrating the temperatures in the ice forward in time, interpolation is used to estimate initial thickness of the melt. The model boundary conditions are then changed for the next time step to the appropriate configuration. At the end of each time step the forcing fluxes are updated, and the thickness of each layer is updated.

\section{Forcing Data}

[62] The model input forcing data are: incoming shortwave radiation, incoming long-wave radiation, air temperature at $10 \mathrm{~m}$ (used in determining the sensible heat flux), specific humidity at $10 \mathrm{~m}$ (used in determining the latent heat flux), air pressure (used in determining the latent heat flux), wind speed at $10 \mathrm{~m}$ (used in determining the latent and sensible heat fluxes), and ocean heat flux. The model forcing was assumed to have no diurnal variation, and varied continuously throughout the annual cycle. Diurnal variation was not considered because it would reduce the accuracy of the model in the early melt season where there could be rapid melt/freeze cycles. Atmospheric SHEBA data were obtained from the online CODIAC system provided by JOSS/UCAR (www.joss.ucar.edu/sheba/) and are derived from data from the SHEBA Surface Flux Group. An assumed profile of the form $X_{\mathrm{LW}}+Y_{\mathrm{LW}} \cos (2 \pi d / 365)$ was fitted to the long-wave data using the method of least squares (where $d$ is day of year), and an assumed profile of the form $\operatorname{Max}\left(0, X_{\mathrm{SW}}+Y_{\mathrm{SW}} \sin (2 \pi(d-249) / 365)\right)$ was fitted to the short-wave data. The best-fit coefficients for the long-wave flux are $X_{\mathrm{LW}}=214.27$ and $Y_{\mathrm{LW}}=-73.81$. The best-fit coefficients for the short-wave flux are $X_{\mathrm{SW}}=29.25$ and $Y_{\mathrm{SW}}=-240.59$. The fitted and observed short- and long-wave fluxes are shown in Figures 3 and 4.

[63] The sensible and latent heat fluxes parameterizations utilize air temperature, specific humidity, air pressure, and wind speed. These were estimated from the SHEBA Surface Flux Group data. The data were averaged for each month, and the average monthly values were interpolated using a cubic spline. Since the data for October were sparse, the averaged September and November value was used. The annual wind speed monthly average was $4.90 \mathrm{~m} / \mathrm{s}$ (compared to $5 \mathrm{~m} / \mathrm{s}$ [Ebert and Curry, 1993]) with standard deviation $0.27 \mathrm{~m} / \mathrm{s}$, and so a constant value of $4.90 \mathrm{~m} / \mathrm{s}$ was used.

[64] Since the aim of our study was not to analyze the interaction between ocean and sea ice, the ocean heat flux was prescribed as an external parameter. For simplicity the ocean heat flux was set to be a constant $2 \mathrm{~W} / \mathrm{m}^{2}[$ Bitz and Lipscomb, 1999]. In reality the ocean heat flux has been observed to have an annual cycle with a summertime peak of over $30 \mathrm{~W} / \mathrm{m}^{2}$ [Perovich and Elder, 2002]. However, the constant ocean heat flux we use is similar to the annual average of previous investigations [Perovich and Elder, 2002], so that the annual mass balance should not be significantly in error.

\section{Simulation Results}

[65] The results of the simulations are now presented. First, the baseline, standard case is described and the quality

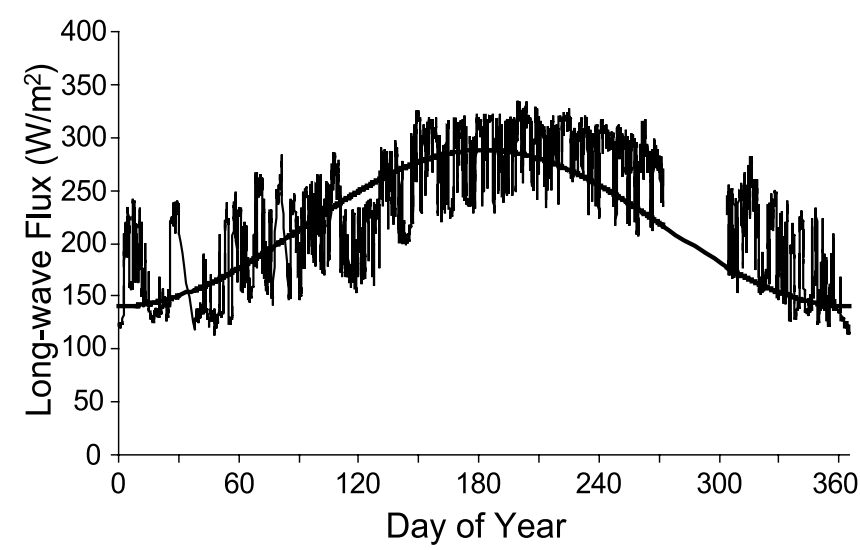

Figure 4. Fitted (thick line) and observed (thin line) seasonal evolution of long-wave radiation $\left(F_{\mathrm{LW}}\right)$. (Day 0 denotes 1 January 1998. Data after day 300 correspond to fall 1997 measurements.) 


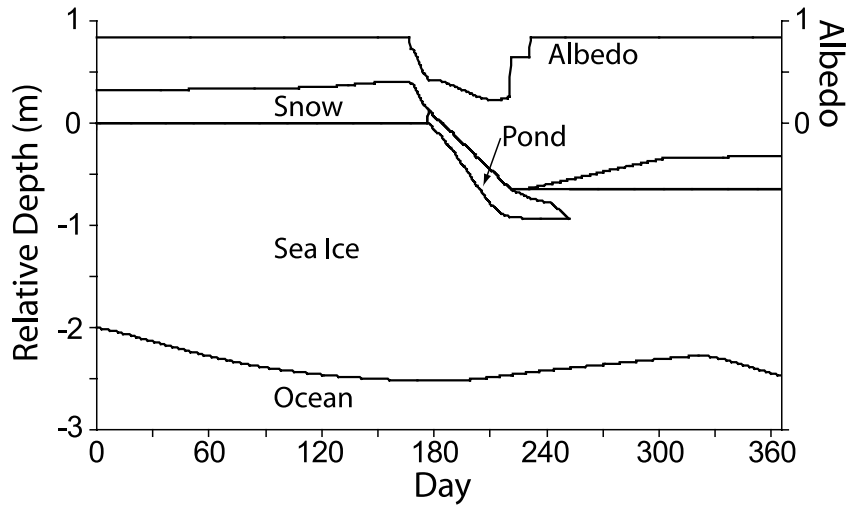

Figure 5. Annual cycle for standard case. Lines indicate motion of boundaries through the year, relative to initial wintertime snow-ice interface (left scale). Uppermost line is the evolution of albedo through the year (right scale). (Day 0 denotes 1 January.)

of the simulation is assessed by comparison to observations at SHEBA and previous modeling. Second, the sensitivity of the model to the drainage rate, initial ice thickness, maximum snow depth, and optical properties is examined.

[66] All model runs are initialized with a linear temperature gradient in the sea ice and the snow and a surface temperature of $-30^{\circ} \mathrm{C}$, consistent with observed wintertime temperature data at SHEBA [Perovich et al., 1999]. In the snow covered case the snow-ice interfacial temperature is determined simply using the condition of conservation of conductive flux at this boundary (equation (34)). The initial ice thickness is set to $2 \mathrm{~m}$, and the initial snow depth is 0.32 $\mathrm{m}$ (consistent with the snow cover formulation described in section 3.4), unless otherwise stated.

[67] The likely long-term fate (after several years) of ice that forms melt ponds will be that it melts completely in summer, with new ice formation through the next season. Therefore, following previous work by Flato and Brown [1996] and Gabison [1987], the melt-pond-sea-ice model is allowed to run for one summer melt season from 1 January to 31 December and is then terminated.

\subsection{Standard Case}

[68] The standard case was chosen to be the simulation with model parameters that gave a reasonable approximation to the expected summertime evolution of melt ponds. Figure 5 shows the evolution of the positions of the boundaries of the melt-pond-sea-ice system. Also shown in the figure is the evolution of the albedo.

[69] During winter the evolution of ice thickness and snow depth is slow, with minor variations at the snow surface due to precipitation and at the ice-ocean interface due to freezing of seawater. As the short-wave energy increases, the temperature of the snow increases until it is warm enough to begin melting, which occurs on day 168 (18 June). When melting begins, the snow albedo drops from its wintertime value (0.84) to its melting value, which is determined from the linearly interpolated value, based on a melting snow value (0.74) at the initial snow thickness and the expected value using the two-stream radiation model at the initial pond depth. The time taken to melt the snow and thus form an initial melt pond is about 9 days, so that on day
177 (27 June), there is a melt pond of depth $0.13 \mathrm{~m}$ with albedo 0.42. As summer continues, the pond deepens and the albedo decreases. The temperature of the pond is in good agreement with observations of pond temperature, a few tenths above freezing [Eicken et al., 1994], with maximum surface temperature $0.74^{\circ} \mathrm{C}$ and maximum core temperature $0.28^{\circ} \mathrm{C}$. On day 213 (2 August) the melt pond is at its maximum depth $(0.33 \mathrm{~m})$, having melted through $0.84 \mathrm{~m}$ of ice, and the albedo is at its minimum value $(0.23)$. On day 221 (10 August) the melt pond has decreased in depth $(0.27 \mathrm{~m})$ and surface ablation has melted $0.92 \mathrm{~m}$ of ice. However, it is at this time that refreezing at the melt pond surface occurs, leading to a rapid increase in albedo up to 0.64 . The reason for this rapid increase is that the wintertime optical properties of the radiation model are incorporated at this point so that a thin layer of sea ice is highly effective at reflecting the incident radiation. Although this sudden increase in refrozen pond albedo is somewhat unrealistic, in practice the refrozen pond is typically covered in a light dusting of snow, which has the effect of increasing the albedo [Perovich et al., 2002]. The constant drainage rate yields a net mass loss of sea ice at the surface of $0.64 \mathrm{~m}$. After only 10 days, on day 231 (20 August), snow begins to fall, and the albedo rises again to its constant wintertime value (0.84). The internal molten region remains as a store of sensible and latent heat, but refreezes by day 253 (11 September). On day 322 (19 November) the sea ice has cooled sufficiently and begins to refreeze at its base. By the end of December the ice has refrozen so that it is $1.83 \mathrm{~m}$ thick, which implies a net annual loss of $0.18 \mathrm{~m}$ of sea ice.

[70] The data available from the SHEBA field experiment provide a necessary check on the simulations. SHEBA melt pond mass balance data of Perovich et al. [1999] using 26 depth gauges indicate that the average maximum pond depth was $0.36 \mathrm{~m}$, with maximum $0.54 \mathrm{~m}$. The amount of surface ablation for all the gauges averaged $0.75 \mathrm{~m}$, with minimum $0.4 \mathrm{~m}$ and maximum $1.09 \mathrm{~m}$. The standard case exhibited maximum pond depth $0.33 \mathrm{~m}$, and $0.92 \mathrm{~m}$ of

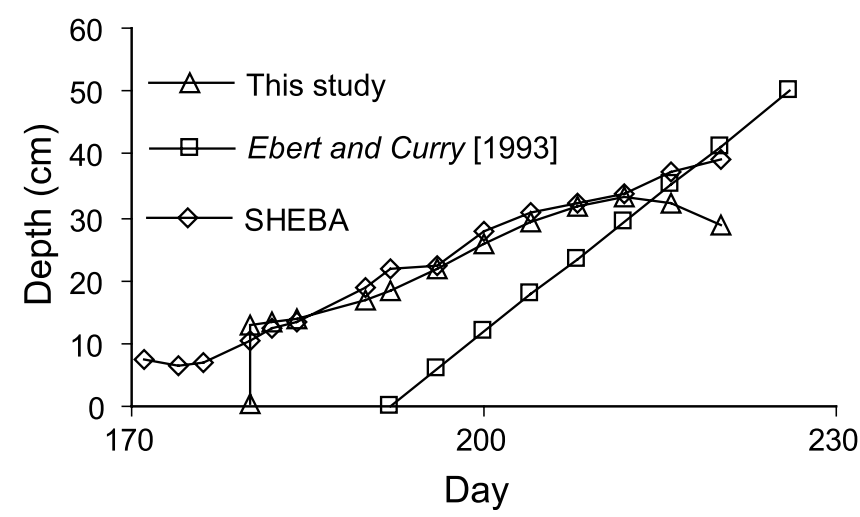

Figure 6. Comparison of melt pond depth evolution: Melt-pond-sea-ice model (standard case); Ebert and Curry's [1993] model; and SHEBA [Perovich et al., 1999] data. Discontinuity in data for melt-pond-sea-ice model represents estimated day that snow cover becomes fully molten and forms a melt pond. (Day 0 denotes 1 January.) 


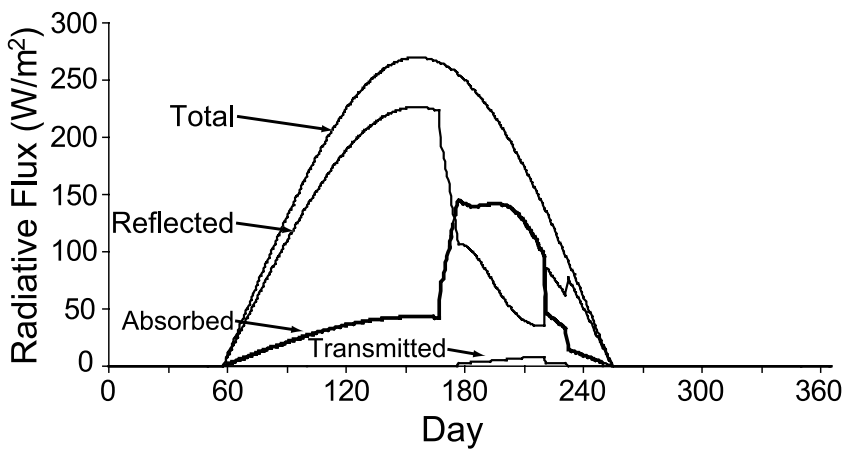

Figure 7. Evolution of short-wave radiation in the meltpond-sea-ice model. Shown are the incoming short-wave radiation (Total), the short-wave radiation that is reflected (Reflected), the short-wave radiation that is absorbed within the whole melt-pond-sea-ice system (Absorbed), and the short-wave radiation that is transmitted through to the ocean (Transmitted). (Day 0 denotes 1 January.)

surface ablation. Therefore the standard case is exhibiting behavior that is similar to observations.

[71] Figure 6 compares the evolution of average pond depths observed at SHEBA [Perovich et al., 1999], with the evolution of pond depth from Ebert and Curry's [1993] model, and the evolution of pond depth from this study. The start of the melt season for the standard case begins late compared to SHEBA data, a feature common among numerical simulations [e.g., Ebert and Curry, 1993; Maykut and Untersteiner, 1971]. The reason for the late start of the melt season is most likely the use of a constant wintertime snow albedo (in reality, this might be expected to decrease as the snow warms before melting). The standard case underestimates the pond depth at the beginning and end of the melt season, although it is remarkably similar during the middle of the melt season. The most likely reason for this is the specification of a constant drainage rate. Melt rates at the surface of sea ice typically wax and wane with the summer season [Perovich et al., 1999], so that the constant drainage rate is an overestimate at the beginning and end of the summer melt season, but yields reasonable total drainage.

[72] Freeze-up in the standard case occurs in mid-August just as in the SHEBA data. Since the surface forcing data are averaged SHEBA data, this similarity between freeze-up dates is evidence to support the use of turbulent heat transport in the melt pond and suggests that the sensible heat stored in the pond is a good approximation.

[73] Figure 7 shows the evolution of the partitioning of the short-wave radiation between the sea ice and melt pond, the ocean, and the atmosphere. The short-wave radiation peaks on day 156 (6 June) at $270 \mathrm{~W} / \mathrm{m}^{2}$, so that when melt ponds form (day 177) the short-wave radiation is decreasing and the absorbed short-wave radiation rapidly triples in value reaching a maximum of $145 \mathrm{~W} / \mathrm{m}^{2}$. Table 1 shows the annual radiative energy budget split into ponded and unponded periods. The total incoming short-wave radiation is comparable to previous models [e.g., Ebert and Curry, 1993; Maykut and Untersteiner, 1971]. Although the melt season is relatively short, the quantity of radiation absorbed during summer in the presence of melt ponds is about the same as the radiation absorbed in the rest of the year.
Table 1. Annual Energy Budget for the Standard Case

\begin{tabular}{lccc}
\hline \multicolumn{1}{c}{ Epoch } & $\begin{array}{c}\text { Ponds Present, } \\
10^{8} \mathrm{~J} / \mathrm{m}^{2}\end{array}$ & $\begin{array}{c}\text { Ponds Absent, } \\
10^{8} \mathrm{~J} / \mathrm{m}^{2}\end{array}$ & $\begin{array}{c}\text { Whole Year, } \\
10^{8} \mathrm{~J} / \mathrm{m}^{2}\end{array}$ \\
\hline Reflected & 2.52 & 17.07 & 19.59 \\
Absorbed & 5.04 & 4.08 & 9.12 \\
Transmitted & 0.21 & 0.02 & 0.23 \\
Total & 7.77 & 21.17 & 28.94 \\
\hline
\end{tabular}

[74] A typical temperature profile for fall (day 250) of the standard case is shown in Figure 8. At this time, the model configuration is at its most complex since it has four separate layers that are tracked at each time step. The air temperature has cooled from its summertime value, of around $0^{\circ} \mathrm{C}$, to $-3.3^{\circ} \mathrm{C}$, and the sensible and latent heat fluxes are directed into the snow and are about $6 \mathrm{~W} / \mathrm{m}^{2}$ and $3 \mathrm{~W} / \mathrm{m}^{2}$, respectively.

[75] Figure 9 shows the evolution of temperature inside the ice from day 0 to day 365 (compare Figure 5). The temperatures observed in the sea ice of the standard case are similar to observed temperature profiles from SHEBA [see Perovich et al., 1999], with the ice steadily becoming isothermal as summer approaches, and are generally lower than those simulated by Maykut and Untersteiner [1971].

[76] Maykut and Untersteiner's [1971] model predicts a more rapid cooling of the sea ice during fall than is observed in field data. This is common in thermodynamic models of sea ice. This effect is sometimes ameliorated by adding latent heat to the model at the surface (at a sufficiently low rate to prevent melting from reoccurring). The melt-pond-sea-ice model presented here does not predict as rapid a cooling as previous models (without latent heat addition), and the ice-ocean interface begins to refreeze in late November. As the internal melt region cools and refreezes, it releases sensible and latent heat to the surrounding sea ice, which diffuses away from the melt region. This extra heat reduces the rate of cooling of the sea ice in fall, consistent with observations, and reduces the temperature gradient in the lower half of the sea ice, leading

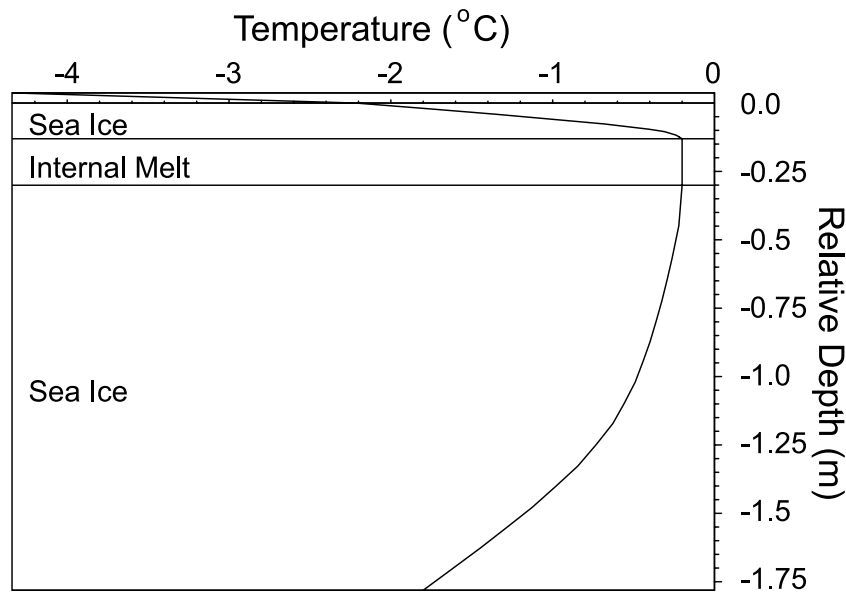

Figure 8. Temperature profile inside melt-pond-sea-ice model at day 250 of the standard case. Snow depth is 0.078 $\mathrm{m}$ and internal melt depth is $0.142 \mathrm{~m}$. Snow-ice interface is at $0 \mathrm{~m}$. 


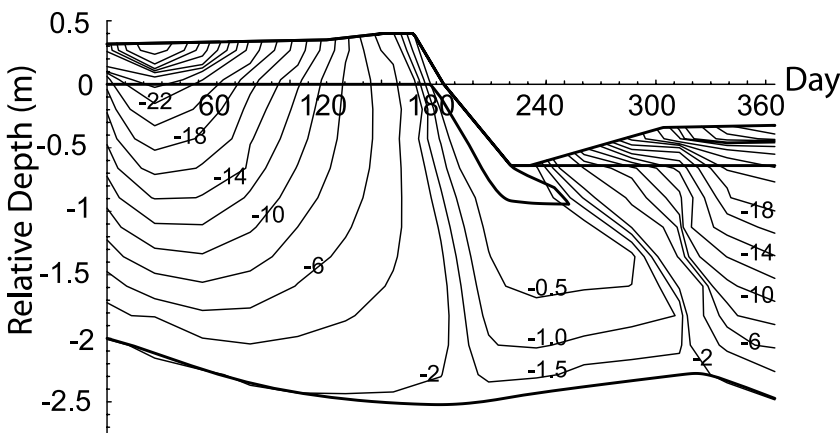

Figure 9. Contour plot of annual evolution of temperature $\left({ }^{\circ} \mathrm{C}\right)$ inside sea ice in the standard case. Moving boundaries are also shown through the year, relative to initial wintertime snow-ice interface. Linear interpolation was used to construct the contour plot onto a uniform grid. (Day 0 denotes 1 January.)

to less wintertime growth. This effect can be seen by comparing the date on which the sea ice begins to refreeze in Figure 5, where there is a melt pond, to Figure 12 in section 5.2.1, where there is only a short-lived melt pond.

\subsection{Model Sensitivity}

[77] Since it is the first time that a melt pond has been explicitly simulated as a separate phase on the sea ice, it is important to understand the sensitivity of the melt-pondsea-ice model to those components that have a large degree of uncertainty. The parameters that we investigate are drainage rate, initial ice thickness, maximum snow depth, and optical properties of sea ice and melt ponds.

[78] To examine sensitivity we perform simulations with different values of the parameter under investigation while holding all other parameters constant and equal to those used in the standard case. The most informative diagnostic of the simulations is the maximum melt pond depth. This is because it can be directly compared to observations and is routinely measured in field studies of melt ponds [e.g., Eicken et al., 1994; Morassutti and LeDrew, 1996; Perovich et al., 1999]. The pond depth is also crucial in determining the albedo of melt pond covered sea ice and is utilized in

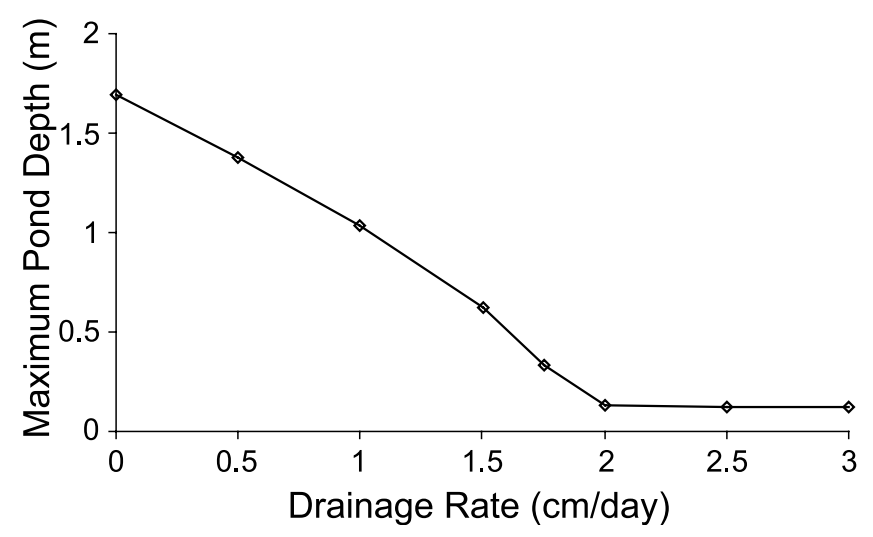

Figure 10. Dependence of maximum pond depth upon drainage rate, with other parameters equal to those used in the standard case.

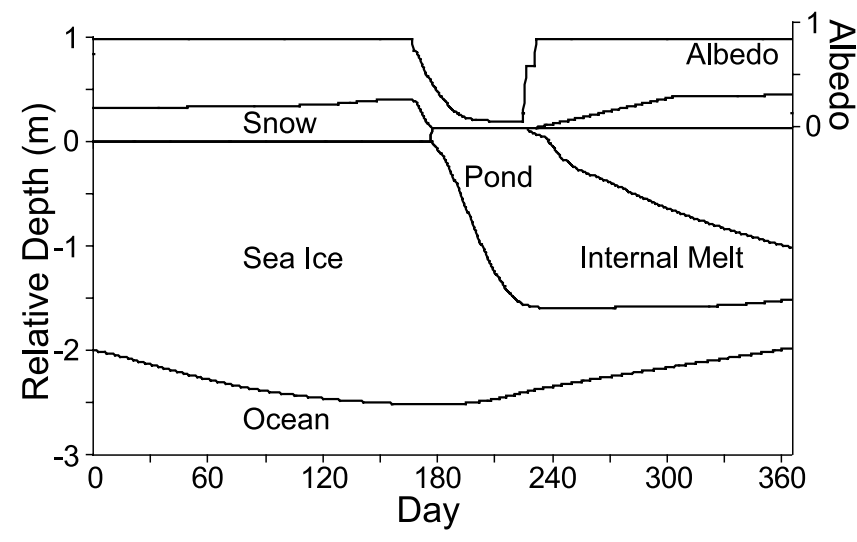

Figure 11. Annual cycle for standard case except that the drainage rate is set to zero. Lines indicate motion of boundaries through the year, relative to initial wintertime snow-ice interface (left scale). Uppermost line is the evolution of albedo through the year (right scale). (Day 0 denotes 1 January 1.)

parameterizations of melt pond albedo [e.g., Ebert and Curry, 1993; Morassutti and LeDrew, 1996].

\subsubsection{Drainage}

[79] Figure 10 shows the dependence of the maximum pond depth on the drainage rate. Qualitatively, there are three types of behavior that are observed as the drainage rate varies. At low drainage rates $(0-1.5 \mathrm{~cm} /$ day $)$, the maximum pond depths are large, which is partly because deeper ponds have a lower albedo which enhances melting at their base (see Figure 11, which shows the evolution of the standard case except that drainage rate is set to zero). At intermediate drainage rates $(1.5-2.0 \mathrm{~cm} /$ day $)$, the maximum pond depths are small, which is partly due to the negative correlation between albedo and pond depth (see Figure 5). At large drainage rates $(>2.0 \mathrm{~cm} /$ day $)$, the drainage rate is so rapid that initial melt ponds formed from snowmelt drain completely (see Figure 12, which shows the evolution of the standard case except that drainage rate is set to $3.5 \mathrm{~cm} /$ day).

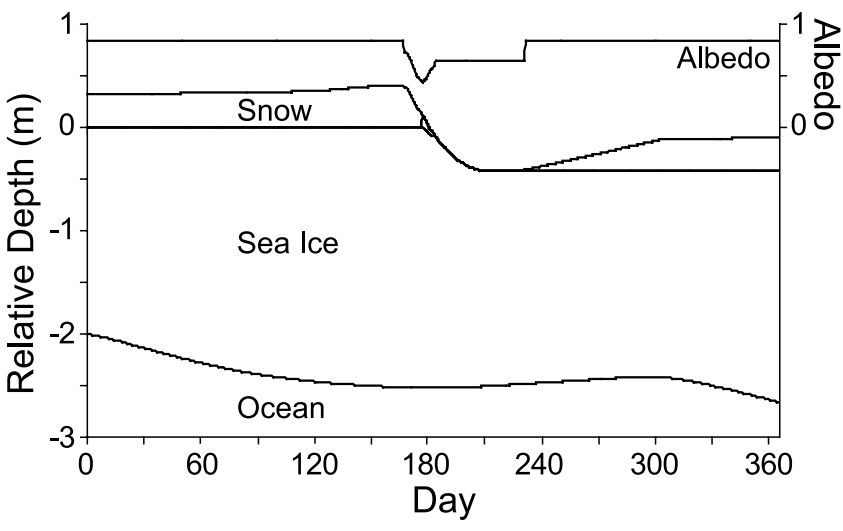

Figure 12. Annual cycle for standard case except that the drainage rate was set to $3.5 \mathrm{~cm} /$ day. Lines indicate motion of boundaries through the year, relative to initial wintertime snow-ice interface (left scale). Uppermost line is the evolution of albedo through the year (right scale). (Day 0 denotes 1 January.) 


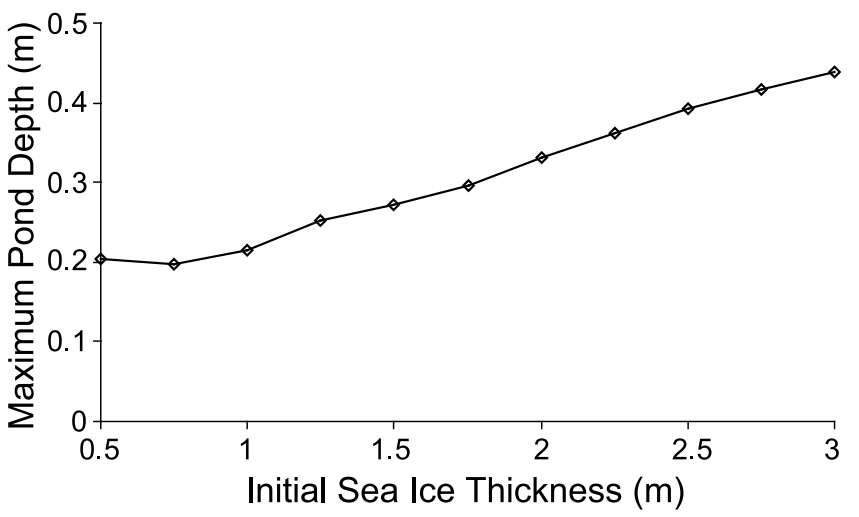

Figure 13. Dependence of maximum pond depth upon initial sea ice depth with other parameters equal to those used in the standard case.

The reason that the maximum pond depth is greater than zero for large drainage rates is that the melt-pond-sea-ice model produces a pond of fixed depth at the beginning of the melt season from melting the initial snow cover. Surface ablation exhibits the same dependence upon drainage rate as the maximum pond depth, since the albedo is correlated to pond depth.

\subsubsection{Initial Ice Thickness}

[80] Intuitively, it might be expected that the albedofeedback mechanism would accelerate melting of ice initially thinner than the standard case due to its lower albedo. However, the maximum pond depth for thinner ice is less than the standard case. The albedo-feedback mechanism is unimportant at this ice thickness because the albedo is relatively insensitive to changes in ice thickness when the ice thickness is greater than about $0.8 \mathrm{~m}$ [Perovich et al., 1986]. The maximum melt pond depth decreases with initial sea ice thickness because of the conductive flux through the sea ice. In the presence of melt ponds, heat is transported away from the pond-ice interface toward the ocean, and thinner ice transports heat away more rapidly. Therefore the melt rate is less rapid, which results in a smaller maximum pond depth. As the initial ice thickness becomes much thinner (less than $0.75 \mathrm{~m}$ ), the albedo-feedback mechanism becomes more effective than the conductive feedback in the summer and so the maximum pond depth increases slightly (see Figure 13).

[81] Measurements at SHEBA revealed excessive bottom melting of the sea ice cover during the field experiment equivalent to $187 \mathrm{MJ} / \mathrm{m}^{2}$ over the year, of which only about two thirds is explained by short-wave radiation entering the ocean through leads [Perovich et al., 2003]. This indicates an energy deficit of about $60 \mathrm{MJ} / \mathrm{m}^{2}$ per year, part of which has been suspected of being transmitted short-wave radiation through the ice and melt ponds into the ocean [Perovich and Elder, 2002; Perovich et al., 2003]. The annual estimate of $23 \mathrm{MJ} / \mathrm{m}^{2}$ (see Table 1) from our standard case calculation accounts for less than half of the missing $60 \mathrm{MJ} / \mathrm{m}^{2}$. Figure 14 shows the variation in total annual transmitted radiation for different initial ice thicknesses. To obtain an annual transmission budget of $60 \mathrm{MJ} / \mathrm{m}^{2}$ requires the initial wintertime ice thickness to be about $1.25 \mathrm{~m}$. This is too thin, since the mean ice thickness at SHEBA was $1.5 \mathrm{~m}$ in October 1997 [Perovich et al., 2003]. Therefore, if the

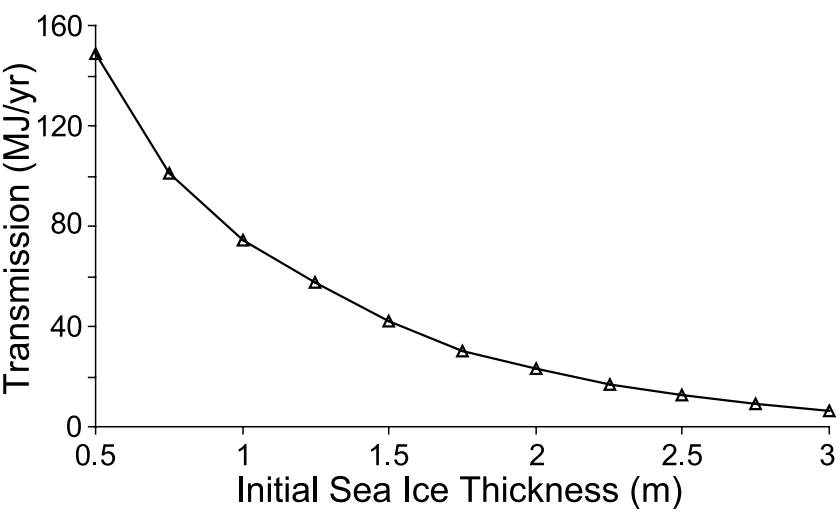

Figure 14. Dependence of annual short-wave transmission into ocean upon initial sea ice depth with other parameters equal to those used in the standard case.

parameter assumptions are valid, it is unlikely that the observed energy deficit is solely due to radiation transmitted through the sea ice cover. Other potential sources for the missing energy, noted by Perovich et al. [2003], are heat advected from the edge of the summer sea ice cover and deep warmer water reaching the underside of the ice contributing to melt.

\subsubsection{Snow Cover}

[82] A snow cover insulates sea ice from the atmosphere, slowing the rate of warming or cooling of the sea ice, and prevents most incoming radiation from entering the sea ice. The net effect of this is to lower the sea ice surface temperature relative to bare sea ice [Sturm et al., 2002].

[83] The sensitivity of the maximum pond depth and maximum surface ablation to the maximum snow depth are shown in Figure 15. The maximum depth of the snow cover was varied by scaling the precipitation rate uniformly throughout the year. The maximum pond depth increases monotonically with maximum snow depth, since the amount of surface water available at the beginning of the melt season is directly proportional to the maximum snow depth. For maximum snow depths greater than $0.3 \mathrm{~m}$, relatively deep ponds are formed that can rapidly melt

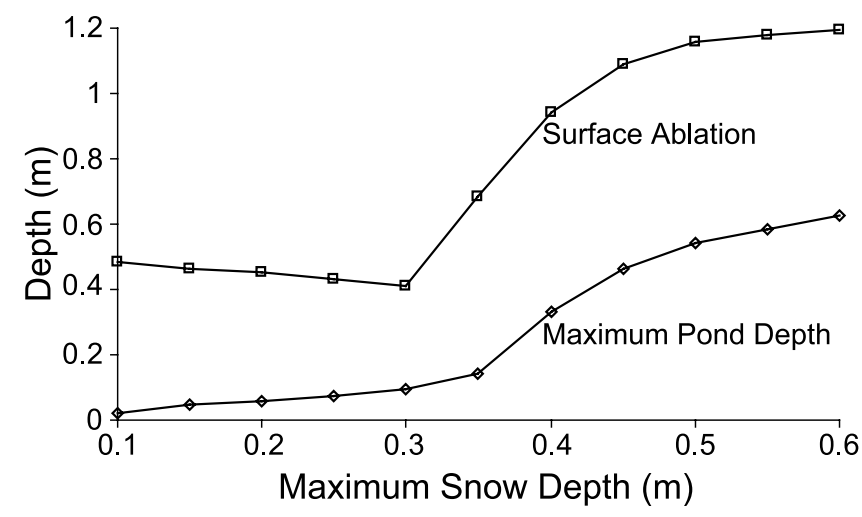

Figure 15. Dependence of maximum surface ablation and maximum pond depth upon maximum snow depth with other parameters equal to those used in the standard case. Snow accumulation rate was scaled uniformly through the year to attain variation in maximum snow depth. 


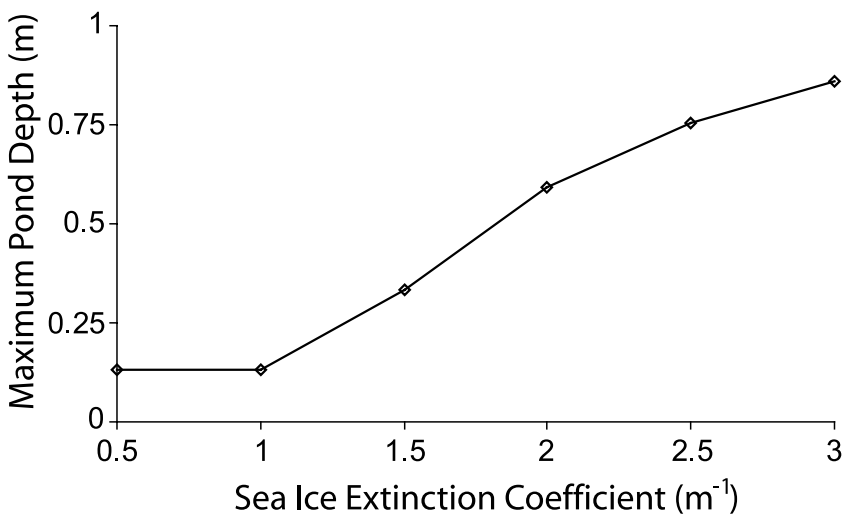

Figure 16. Dependence of maximum pond depth upon sea ice extinction coefficient $\kappa_{2}$ with other parameters equal to those used in the standard case.

through the ice and lead to an increase in maximum surface ablation with increasing maximum snow depth. For maximum snow depths less than $0.3 \mathrm{~m}$, however, the maximum surface ablation increases as maximum snow depth decreases. This behavior is due to thinner snow cover allowing melt ponds to form sooner and hence increase the length of the melt season, which overcompensates the corresponding decrease in melt rate associated with shallower melt ponds.

\subsubsection{Optical Properties}

[84] The optical properties of the melt-pond-sea-ice model are described by two parameters $\left(\kappa_{2}\right.$ and $\left.s_{2}\right)$ for the ice and two parameters $\left(\kappa_{1}\right.$ and $\left.i_{0}^{l}\right)$ for the pond. Figure 16 shows the dependence of the maximum pond depth upon the extinction coefficient of the sea ice $\left(\kappa_{2}\right)$. A lower sea ice extinction coefficient corresponds to proportionally less energy absorbed by the sea ice near the surface than the interior. This allows more sensible heat to be stored within the interior of the ice, so that less energy can contribute to surface melting, in agreement with the results of Maykut and Untersteiner [1971]. The result of this is that lower sea ice extinction coefficients lead to ponds that are shallower and with smaller surface ablation.

[85] Figure 17 shows the sensitivity of the maximum pond depth to the sea ice albedo proxy $s_{2}$. Lower sea ice

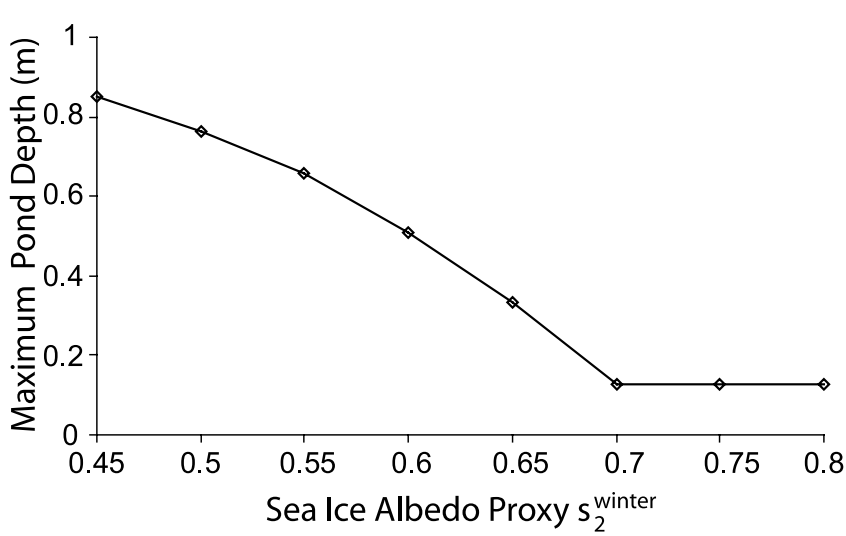

Figure 17. Dependence of maximum pond depth upon sea ice albedo proxy $s_{2}{ }^{\text {winter }}$ with other parameters equal to those used in the standard case.

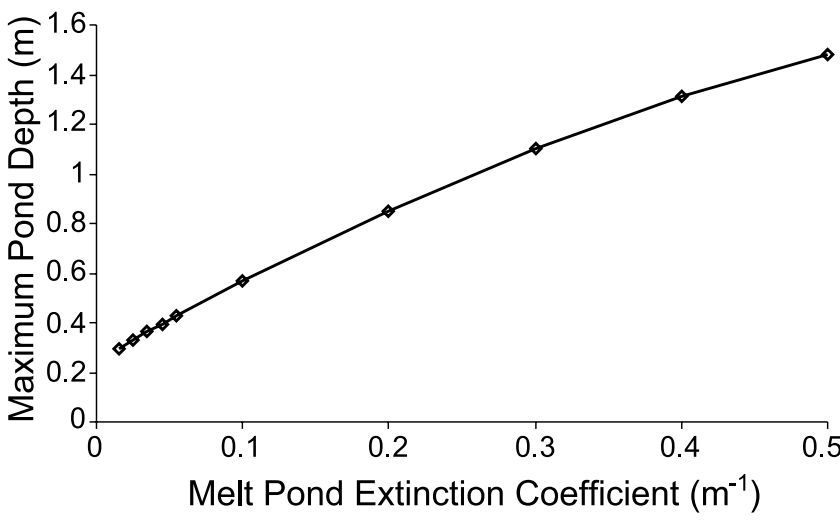

Figure 18. Dependence of maximum pond depth upon melt pond extinction coefficient $\kappa_{1}$ with other parameters equal to those used in the standard case.

albedo $s_{2}$ corresponds to larger pond depths and increased surface ablation since more short-wave radiation can enter the melt pond and sea ice.

[86] The optical properties of a melt pond are simpler than those of sea ice in that a pond does not have the same temporally evolving morphological complexity. However, the optical properties of the pond can be affected by biological and particulate inclusions (e.g., soot), which can either be in suspension or accumulate at the base of ponds. The effect of suspended inclusions is to increase the absorption coefficient of the pond. Figure 18 shows the sensitivity of the maximum pond depth to the extinction coefficient of the melt pond. As the absorption coefficient of the pond increases, the pond can convert more short-wave radiation into heat, and also there is a decrease in albedo. Both of these effects result in larger pond depths and more sea ice ablation as the extinction coefficient increases.

[87] The $i_{0}^{l}$ parameter for the melt pond determines the amount of radiation that passes through the surface of the pond and contributes to internal heating. This is highly uncertain because the amount of radiation that can pass through the surface depends on the spectral composition of the incident radiation. Clouds absorb longer wavelength

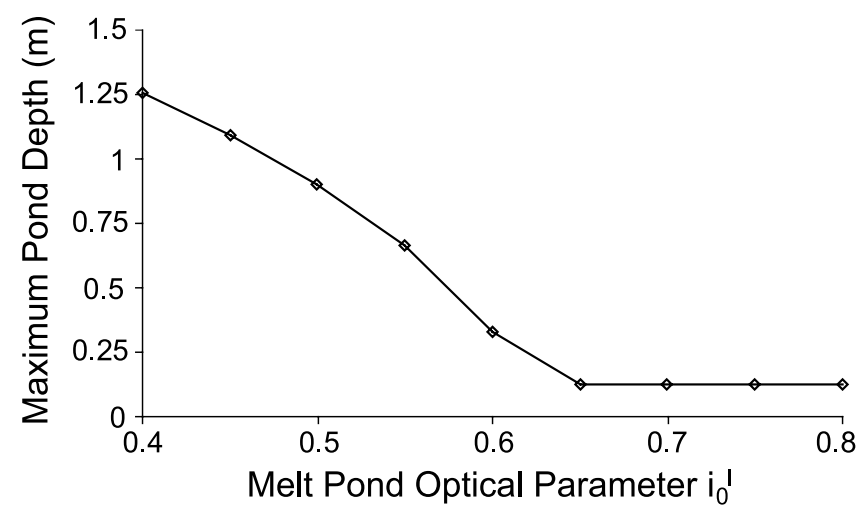

Figure 19. Dependence of maximum pond depth upon fraction of short-wave radiation penetrating into melt pond and sea ice $i_{0}{ }^{l}$ at standard drainage rate with other parameters equal to those used in the standard case. 
Table 2. Sensitivity Parameter $\delta_{\text {sens }}$ for Variables Against Which the Maximum Melt Pond Depth Sensitivity Was Examined ${ }^{\mathrm{a}}$

\begin{tabular}{lr}
\hline \multicolumn{1}{c}{ Parameter } & \multicolumn{1}{c}{$\delta_{\text {sens }}$} \\
\hline Drainage & -5.228 \\
Initial ice thickness & 0.801 \\
Maximum snow depth & 3.820 \\
Sea ice extinction $\kappa_{2}$ & 2.103 \\
Ice albedo proxy $s_{2}$ & -7.513 \\
Melt pond extinction $\kappa_{1}$ & 0.245 \\
Melt pond parameter $i_{0}{ }^{l}$ & -9.685 \\
\hline
\end{tabular}

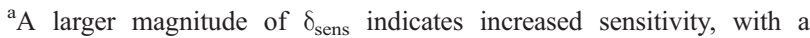
positive sign indicating that an increase in the parameter leads to an increase in the maximum pond depth, and vice versa.

radiation more strongly than shorter wavelength radiation [Perovich, 1996]. Therefore, when it is cloudy the $i_{0}^{l}$ parameter for the melt pond is larger than when it is clear.

[88] Figure 19 shows the sensitivity of the maximum pond depth to a wide range of values of $i_{0}^{l}$. As $i_{0}^{l}$ increases, the radiative heating of the melt pond and sea ice increases; however, increasing $i_{0}^{l}$ decreases the magnitude of the turbulent convective heat flux in the melt pond at the atmosphere-pond interface, which can be seen from the surface energy balance (equation (28)). The turbulent convective heat flux into the pond is more sensitive to variations in $i_{0}^{l}$ than the radiative heating of the pond due to short-wave radiation, so that increasing $i_{0}^{l}$ leads to a decrease in the maximum pond depth.

\subsubsection{Comparison of Model Sensitivity}

[89] We define a measure of model sensitivity $\delta_{\text {sens }}(x)$, where $x$ is the parameter being considered, as the nondimensionalized partial derivative of the maximum pond depth with respect to parameter $x$, in a similar way to Ebert and Curry [1993]. The scales used for nondimensionalization are determined by the standard case values of the maximum pond depth and the parameter being considered. The partial derivative is determined using a central finite difference scheme. The model sensitivity is

$$
\delta_{\text {sens }}(x)=\frac{\langle x\rangle}{\left\langle H_{\text {pond }}^{\max }\right\rangle} \frac{\partial H_{\text {pond }}^{\max }}{\partial x}
$$

where angle brackets denote the value at the standard case, and $H_{\text {pond }}^{\max }$ is the maximum pond depth. The value of $\delta_{\text {sens }}$ is a local measure of sensitivity in the vicinity of the standard case parameters. If $\delta_{\text {sens }}(x)$ is positive, then increases in parameter $x$ result in increases in the maximum pond depth, and vice versa. The magnitude of the sensitivity parameter indicates the strength of the sensitivity, with larger magnitudes corresponding to increased sensitivity.

[90] Table 2 shows the value of the sensitivity measure $\delta_{\text {sens }}$ for the parameters investigated in section 5.2. The maximum melt pond depth was most sensitive to the melt pond optical parameter $i_{0}$, because of its influence on the surface energy balance. The least influential parameter was the melt pond extinction coefficient. This is because the total amount of radiation absorbed by the pond is relatively small in comparison to the turbulent heat fluxes at the boundaries (equation (26)). However, it should be noted that the sensitivity parameter is only a local estimate of sensitivity, and since the model is nonlinear, the sensitivity parameter may vary across parameter space.

\section{Summary and Conclusions}

[91] Previous work has parameterized melt ponds [e.g., Ebert and Curry, 1993; Maykut and Untersteiner, 1971; Mellor and Kantha, 1989]. The current work describes an explicit, physically based model of melt ponds on sea ice.

[92] The thermodynamic component of the sea ice model is described using the equations describing a mushy layer, so that the sea ice is assumed to consist of a solid matrix of pure ice surrounded by brine (there are no air pockets). The simplifying assumption of constant density of each phase removes dynamic effects due to phase change. The melt pond salinity is assumed to remain constant due to mixing as the pond undergoes turbulent convection.

[93] The two-stream radiation model is used because it enables albedo to be obtained from optical properties describing the sea ice, instead of prescribing albedo as an external parameter. The two-stream model is reformulated in terms of the sea ice albedo proxy, $s_{2}$, a combination of the absorption $\left(k_{2}\right)$ and extinction $\left(\kappa_{2}\right)$ coefficients. The radiation field in each layer of the two-stream model is determined by two unknown parameters, calculated from the upper and lower boundary conditions of each layer. The optical properties and incident radiation are assumed to be independent of wavelength. However, this should not affect the qualitative results of the thermodynamic model provided that the radiation near the surface is adequately modeled.

[94] The sea ice optical property $s_{2}$ is parameterized to account for summertime variation. As expected, the interaction of radiation with sea ice, snow, and melt ponds is fundamental to controlling summertime melt. The melt pond depth is most sensitive to the optical properties (Table 2), which is probably because the optical parameter $s_{2}$ was dependent on the melt pond depth. The ability of the simulation to replicate albedo variations observed during summertime [Perovich et al., 2002] lends confidence to the parameterization of $s_{2}$. Further work is warranted in order to refine this type of parameterization of optical properties during summer.

[95] The melt rate beneath melt ponds is related to pond depth through the dependence of radiative heating, due to the albedo-feedback mechanism, on pond depth, and the dependence of the conductive flux through the sea ice to the ocean on ice thickness. In the presence of melt ponds the complexity of feedback mechanisms that affect the mass balance of the sea ice is increased.

[96] A simple snow cover model was utilized, following Maykut and Untersteiner [1971], since we focused on the effect of melt ponds. To conserve mass and energy as the snowmelts and forms a melt pond, a nonlinear relationship between density and volume was imposed.

[97] Drainage of melt ponds on sea ice is complicated, since it is the net result of drainage through the base of melt ponds and accumulation due to lateral water transport into the pond through permeable sea ice. Calculations of vertical drainage through permeable sea ice of a meltwater head show it to be rapid, with timescales of the order of minutes for permeabilities of about $10^{-10} \mathrm{~m}^{2}$ [Taylor, 2003]. Even in the early melt season with permeabilities as low as $10^{-12} \mathrm{~m}^{2}$ 
the timescale of drainage is of the order of several days. To maintain a steady meltwater head above sea level requires that the lateral accumulation balances the drainage out of the pond. However, the total mass necessary to maintain such a meltwater head above sea level is disproportionately large [Taylor, 2003]. The result is that on average the surface of sufficiently large melt ponds (lateral size $\sim 2 \mathrm{~m}$ ) should be maintained at sea level, and drainage is therefore fixed by the change in relative sea level of the entire sea ice floe.

[98] Ebert and Curry [1993] utilized the runoff fraction in their sea ice model as a tunable parameter, in a way similar to that in which Maykut and Untersteiner [1971] used the sea ice albedo to tune their model. It is a common feature of sea ice models that there is such a large degree of uncertainty within model parameters that they can be tuned within error estimates of parameters to resemble reality [Shine and Henderson-Sellers, 1985]. In the melt-pondsea-ice model presented here, the inherent uncertainty and obvious variability of the drainage rate means that this could be tuned within reasonable bounds, for example, $0-$ $5 \mathrm{~cm} /$ day. Future research should re-evaluate the assumption of a constant drainage rate, by considering factors such as temporal evolution of permeability of sea ice.

[99] It has been pointed out [Eicken et al., 2002] that the hydrology of the ice affects the temporal evolution of sea ice albedo. This follows because the depth of the pond is negatively correlated with its albedo. The significant sensitivity to the drainage parameter in the melt-pond-sea-ice model (see Table 2) chimes well with the requirement of incorporating hydrology into a determination of sea ice albedo.

[100] Previous research has assumed that the influence of melt ponds on the overall mass balance of sea ice is relatively small since they refreeze in fall [Maykut and Untersteiner, 1971]. However, the calculations presented here using our new melt-pond-sea-ice model indicate that the presence of melt ponds affect the mass balance significantly through the albedo-feedback mechanism, drainage, and through the delayed onset of refreezing at the ice-ocean interface caused by sensible and latent heat storage in refreezing melt ponds. The model simulations compare favorably with SHEBA field data.

\section{Notation}

$\alpha^{*}$ coefficient of thermal expansion of pond, equal to $5 \times 10^{-5} \mathrm{~K}^{-1}$.

$\alpha_{\infty}^{\text {pond }}$ albedo of pond-covered sea ice in limit of infinite ice thickness.

$\alpha_{\infty}$ albedo of single layer of sea ice in limit of infinite thickness, equal to 0.65 .

$\alpha$ total albedo.

$\alpha_{\lambda}$ spectral albedo at wavelength $\lambda$.

$\delta$ dendrite (platelet) spacing inside sea ice, $\mathrm{m}$.

$\delta_{\text {sens }}(x)$ sensitivity of maximum melt pond depth for a simulation to parameter $x$.

$\epsilon^{x} \quad$ emmisivity of surface type $x$.

$\zeta$ transformed temporal coordinate, s.

$\gamma$ constant of proportionality for turbulent heat flux, 0.1 .

$\Gamma$ gradient of linearized liquidus curve, equal to $0.0514 \mathrm{~K} / \mathrm{ppt}$. $\kappa_{i}$ extinction coefficient in layer $i, \mathrm{~m}^{-1}$.

$\kappa_{l}$ thermal diffusivity of pond, equal to $1.19 \times 10^{-7}$ $\mathrm{m}^{2} / \mathrm{s}$.

$\lambda$ wavelength, $\mathrm{nm}$.

$\nu_{l}$ kinematic viscosity of pond, equal to $10^{-6} \mathrm{~m}^{2} / \mathrm{s}$.

$\xi$ transformed spatial coordinate.

$\rho_{a}$ density of air, equal to $1.275 \mathrm{~kg} / \mathrm{m}^{3}$.

$\rho_{s} \mathcal{L}$ volumetric latent heat of fusion of pure ice, equal to $3.0132 \times 10^{8} \mathrm{~J} / \mathrm{m}^{3}$.

$\rho_{\text {snow }}$ density of snow, $\mathrm{kg} / \mathrm{m}^{3}$.

$(\rho c)_{l}$ volumetric specific heat capacity of brine or pond, equal to $4.185 \times 10^{6} \mathrm{~J} /\left(\mathrm{m}^{3} \mathrm{~K}\right)$.

$(\rho c)_{m}$ volumetric specific heat capacity of sea ice, $\mathrm{J} /\left(\mathrm{m}^{3} \mathrm{~K}\right)$.

$(\rho c)_{s}$ volumetric specific heat capacity of pure ice, equal to $1.883 \times 10^{6} \mathrm{~J} /\left(\mathrm{m}^{3} \mathrm{~K}\right)$.

$\sigma$ Stefan-Boltzmann constant, equal to $5.67 \times$ $10^{-8} \mathrm{~J} /\left(\mathrm{K}^{4} \mathrm{~m}^{2} \mathrm{~s}\right)$.

$\tau$ optimal parameter for assumed form of optical parameter $s_{2}$, equal to $3.55 \mathrm{~m}^{-1}$.

$\phi$ local solid fraction inside sea ice.

$\chi^{x}$ heat flux at surface of surface type $x, \mathrm{~W} / \mathrm{m}^{2}$.

$a$ coefficient in snow density-thickness relationship, $\mathrm{kg} / \mathrm{m}^{5}$.

$A^{i} \quad$ optical parameter dependent on optical properties and thickness in layer $i, \mathrm{~W} / \mathrm{m}^{2}$.

$b$ coefficient in snow density-thickness relationship, $\mathrm{kg} / \mathrm{m}^{4}$.

$B^{i} \quad$ optical parameter dependent on optical properties and thickness in layer $i, \mathrm{~W} / \mathrm{m}^{2}$.

$c$ coefficient in snow density-thickness relationship, $\mathrm{kg} / \mathrm{m}^{3}$.

$c_{a}$ specific heat capacity of air, equal to $1005 \mathrm{~J} /(\mathrm{kg}$ $\mathrm{K})$.

$c_{\text {snow }}$ specific heat capacity of snow, equal to $2092 \mathrm{~J} /$ (kg K).

$C$ concentration of brine inside sea ice, ppt.

$C_{\text {bulk }}$ local bulk salinity, equal to $3.2 \mathrm{ppt}$.

$C^{i}$ optical parameter dependent on optical properties and thickness in layer $i, \mathrm{~W} / \mathrm{m}^{2}$.

$C_{\text {ocean }}$ salinity of ocean, equal to $35 \mathrm{ppt}$.

$C_{\text {pond }}$ salinity of pond, equal to $3.9 \mathrm{ppt}$.

$C_{S}$ salinity of pure ice, equal to $0 \mathrm{ppt}$.

$C_{T}^{x} \quad$ stability dependent transfer coefficient of surface type $x$.

$d$ day of year.

$D^{i} \quad$ optical parameter dependent on optical properties and thickness in layer $i, \mathrm{~W} / \mathrm{m}^{2}$.

$D_{l}$ solutal diffusivity in brine, $\mathrm{m}^{2} / \mathrm{s}$.

$\left(E_{\text {net }}\right)_{0}^{x}$ net energy at surface of surface type $x, \mathrm{~W} / \mathrm{m}^{2}$.

$F_{\downarrow i} \quad$ downwelling irradiance in layer $i, \mathrm{~W} / \mathrm{m}^{2}$.

$F_{\uparrow i}$ upwelling irradiance in layer $i, \mathrm{~W} / \mathrm{m}^{2}$.

$F_{c}\left(T^{*}\right)$ heat flux out of pond or internal melt region, $\mathrm{W} / \mathrm{m}^{2}$.

$F_{\text {lat }}^{x}$ latent heat flux of surface type $x, \mathrm{~W} / \mathrm{m}^{2}$.

$F_{L W}$ incoming long-wave flux, $\mathrm{W} / \mathrm{m}^{2}$.

$F_{\text {net }(i)}\left(z_{i}\right)$ net irradiance at position $z_{i}$ in layer $i, \mathrm{~W} / \mathrm{m}^{2}$.

$F_{\text {net }}(z)$ net-irradiance measure with respect to uppermost surface of model, $\mathrm{W} / \mathrm{m}^{2}$.

$F_{\text {ocean }}$ ocean heat flux, equal to $2 \mathrm{~W} / \mathrm{m}^{2}$.

$F_{\text {sens }}^{x}$ sensible heat flux of surface type $x, \mathrm{~W} / \mathrm{m}^{2}$.

$F_{\text {SW }}$ incident short-wave irradiance, $\mathrm{W} / \mathrm{m}^{2}$. 
$g$

magnitude of acceleration due to gravity, equal to $9.8 \mathrm{~m} / \mathrm{s}^{2}$.

$h_{i}$ position of ice-ocean interface, $\mathrm{m}$.

$h_{l}$ position of lower boundary of liquid region, $\mathrm{m}$.

$h_{p}$ position of lower-ice-pond interface, $\mathrm{m}$.

$h_{s}$ position of surface, $\mathrm{m}$.

$h_{s}{ }^{*}$ position of snow-atmosphere interface after initial melting has occurred, $\mathrm{m}$.

$h_{\text {snow }}$ position of snow-ice interface, $\mathrm{m}$.

$h_{u}$ position of upper boundary of liquid region, $\mathrm{m}$.

$h_{\mathrm{ui}}$ position of upper-ice-pond interface, $\mathrm{m}$.

$H_{i}$ depth of layer $i, \mathrm{~m}$.

$H_{\text {snow }}$ depth of snow layer, $\mathrm{m}$.

$i_{0}^{x}$ fraction of incident radiation that penetrates surface of surface type $x$.

$J$ turbulent heat flux factor, equal to $1.907 \times$ $10^{-5} \mathrm{~m} /\left(\mathrm{s} \mathrm{K}^{1 / 3}\right)$.

$k_{i} \quad$ absorption coefficient in layer $i, \mathrm{~m}^{-1}$

$k_{l}$ thermal conductivity of brine or pond, equal to $0.5 \mathrm{~W} /(\mathrm{m} \mathrm{K})$.

$k_{m}$ thermal conductivity of sea ice, $\mathrm{W} /(\mathrm{m} \mathrm{K})$.

$k_{s}$ thermal conductivity of pure ice, equal to $2 \mathrm{~W} /(\mathrm{m} \mathrm{K})$.

$k_{\text {snow }}$ thermal conductivity of snow, equal to $0.31 \mathrm{~W} /(\mathrm{m} \mathrm{K})$.

$\mathcal{L}^{*}$ latent heat of vaporization, equal to $2.501 \times$ $10^{6} \mathrm{~J} / \mathrm{kg}$.

$\mathcal{L}_{\text {snow }}$ latent heat of snow, equal to $332424 \mathrm{~J} / \mathrm{kg}$

$p_{\text {atm }}$ atmospheric pressure, $\mathrm{kPa}$.

$p_{v}$ partial pressure of water vapor, $\mathrm{kPa}$.

$q_{0} \quad$ specific humidity at surface.

$q_{a}$ specific humidity of air at reference height.

$r_{i}$ scattering coefficient in layer $i, \mathrm{~m}^{-1}$.

$R_{0}$ fresnel reflection coefficient, equal to 0.05 .

$\operatorname{Ra}(t)$ time-dependent Rayleigh number.

$\mathrm{Ra}_{\text {crit }}$ critical Rayleigh number, equal to 630 .

$s_{2}^{\text {winter }}$ constant value of optical parameter $s_{2}$ used during winter, equal to 0.643 .

$s_{i} \quad$ optical parameter dependent on absorption and extinction coefficient in layer $i$.

$t$ time, s.

$\Delta T$ temperature difference across pond (surface minus base), $\mathrm{K}$.

$\bar{T}$ mean temperature of turbulent pond, $\mathrm{K}$.

$T_{0}$ surface temperature, $\mathrm{K}$.

$T$ temperature, $\mathrm{K}$.

$T_{\text {ice }}{ }^{*}$ temperature of snow-ice interface before initial melting has occurred, $\mathrm{K}$.

$T_{l}$ temperature of lower boundary of liquid region, equal to $272.8 \mathrm{~K}$.

$T_{L}(0)$ equilibrium freezing temperature at zero concentration, equal to $273 \mathrm{~K}$.

$T_{L}(C)$ equilibrium freezing temperature of sea ice at concentration $C, \mathrm{~K}$.

$T_{u}$ temperature of upper boundary of liquid region, $\mathrm{K}$.

$u$ velocity of fluid in pond, $\mathrm{m} / \mathrm{s}$.

$U$ Darcy velocity of brine inside sea ice, $\mathrm{m} / \mathrm{s}$.

$v$ wind speed at reference height, equal to $4.9 \mathrm{~m} / \mathrm{s}$.

$\langle x\rangle$ value of parameter $x$ for a standard case simulation

$H_{\text {pond }}^{\max }$ maximum pond depth, m.
$X_{\mathrm{LW}} \quad$ coefficient of long-wave parameterization, equal to $214.27 \mathrm{~W} / \mathrm{m}^{2}$.

$X_{\mathrm{SW}}$ coefficient of short-wave parameterization, equal to $29.25 \mathrm{~W} / \mathrm{m}^{2}$.

$Y_{\mathrm{SW}}$ coefficient of short-wave parameterization, equal to $-240.59 \mathrm{~W} / \mathrm{m}^{2}$.

$Y_{\mathrm{LW}}$ coefficient of long-wave parameterization, equal to $-73.81 \mathrm{~W} / \mathrm{m}^{2}$.

$z_{i}$ relative position measured vertically down with respect to layer $i(i=0,1,2), \mathrm{m}$.

[101] Acknowledgments. We thank our colleagues in the SHEBA Atmospheric Surface Flux Group, Ed Andreas, Chris Fairall, Peter Guest, and Ola Persson, for help collecting and processing the data. The National Science Foundation supported this research with grants to the U.S. Army Cold Regions Research and Engineering Laboratory, NOAA's Environmental Technology Laboratory, and the Naval Postgraduate School. P. D. T. was supported by a NERC/Met Office CASE award (NER/S/A/2000/ 03685) during this research.

\section{References}

Andreas, E. L., and S. F. Ackley (1982), On the differences in ablation seasons of Arctic and Antarctic sea ice, J. Atmos. Sci., 39, 440-447.

Bitz, C. M., and W. H. Lipscomb (1999), An energy-conserving thermodynamic model of sea ice, J. Geophys. Res., 104(C7), 15,669-15,677.

Bogorodskii, P. V. (1995), Convection in a puddle, Russ. Meteorol. Hydrol., $1,39-43$.

Cattle, H., and J. Crossley (1995), Modelling Arctic climate change, Philos. Trans. R. Soc. London, Ser. A, 352, 201-213.

Cox, G. F. N., and W. F. Weeks (1974), Salinity variations in sea ice, J. Glaciol., 13(67), 109-120.

Ebert, E. E., and J. A. Curry (1993), An intermediate one-dimensional thermodynamic sea ice model for investigating ice-atmosphere interactions, J. Geophys. Res., 98(C6), 10,085-10,109.

Eicken, H., et al. (1994), Distribution, structure and hydrography of surface melt puddles, Ber. Polarforsch., 149, 73-76.

Eicken, H., R. Gradinger, B. Ivanov, A. Makshtas, and R. Pác (1996), Surface melt puddles on multi-year sea ice in the Eurasian Arctic, in Proceedings of ACSYS Conference on the Dynamics of the Arctic Climate System, WMO/TD 760, pp. 267-271, World Meteorol. Org., Göteborg, Sweden.

Eicken, H., H. R. Krouse, D. Kadko, and D. K. Perovich (2002), Tracer studies of pathways and rates of meltwater transport through Arctic summer sea ice, J. Geophys. Res., 107(C10), 8046, doi:10.1029/ 2000JC000583.

Feltham, D. L., and M. G. Worster (1999), Flow induced morphological instability of a mushy layer, J. Fluid Mech., 391, 337-357.

Feltham, D. L., and M. G. Worster (2000), Similarity solutions describing the melting of a mush, J. Cryst. Growth, 208, 746-756.

Ferguson, S. H., M. K. Taylor, and F. Messier (2000), Influence of sea ice dynamics on habitat selection by polar bears, Ecology, 81(3), 761-772.

Fetterer, F., and N. Untersteiner (1998), Observations of melt ponds on Arctic sea ice, J. Geophys. Res., 103(C11), 24,821-24,835.

Flato, G. M., and R. D. Brown (1996), Variability and climate sensitivity of landfast Arctic sea ice, J. Geophys. Res., 101(C10), 25,767-25,777.

Gabison, R. (1987), A thermodynamic model of the formation, growth, and decay of first-year sea ice, J. Glaciol., 33(13), 105-119.

Gradinger, R. (1996), Occurrence of an algal bloom under Arctic pack ice, Mar. Ecol. Prog. Ser., 131, 301-305.

Grenfell, T. C. (1979), The effects of ice thickness on the exchange of solar radiation over the polar oceans, J. Glaciol., 22(87), 305-320.

Grenfell, T. C., and G. A. Maykut (1977), The optical properties of ice and snow in the Arctic Basin, J. Glaciol., 18, 445-463.

Hale, G. M., and M. R. Querry (1973), Optical constants of water in the $200 \mathrm{~nm}$ to $200 \mu \mathrm{m}$ wavelength region, Appl. Opt., 12, 555-563.

Huppert, H. E. (2000), Geological fluid mechanics, in Perspectives in Fluid Dynamics: A Collective Introduction to Current Research, edited by G. K. Batchelor, H. K. Moffatt, and M. G. Worster, pp. 447-506, Cambridge Univ. Press, New York.

Kovacs, A. (1996), Sea Ice: I. Bulk salinity versus floe thickness, Tech. Rep. 96-7, U.S. Army Corps of Eng., Cold Reg. Res. Eng. Lab., Hanover, N. H.

Laxon, S., N. Peacock, and D. Smith (2003), High interannual variability of sea ice thickness in the Arctic region, Nature, 425, 947-950.

Linden, P. F. (2000), Convection in the environment, in Perspectives in Fluid Dynamics: A Collective Introduction to Current Research, edited 
by G. K. Batchelor, H. K. Moffatt, and M. G. Worster, pp. 289-345, Cambridge Univ. Press, New York.

Makshtas, A. P., E. L. Andreas, P. N. Svyashchennikov, and V. F. Timachev (1998), Accounting for clouds in sea ice models, Tech. Rep. 98-9, U.S Army Corps of Eng., Cold Reg. Res. Eng. Lab., Hanover, N. H.

Maykut, G. A. (1996), Modeling interactions between shortwave radiation, pack ice and the upper ocean, in Proceedings of the ACSYS Conference on the Dynamics of the Arctic Climate System, WMO/TD 760, pp. 55-59, World Meteorol. Org., Göteborg, Sweden.

Maykut, G. A., and B. Light (1995), Refractive-index measurements in freezing sea ice and sodium chloride brines, Appl. Opt., 34(6), 950961.

Maykut, G. A., and N. Untersteiner (1969), Numerical prediction of the thermodynamic response of Arctic sea ice to environmental changes, Tech. Rep. RM-6093-PR, RAND Corp., Santa Monica, Calif.

Maykut, G. A., and N. Untersteiner (1971), Some results from a timedependent, thermodynamic model of sea ice, J. Geophys. Res., 76(6), $1550-1575$.

Mellor, G. L., and L. Kantha (1989), An ice-ocean coupled model, J. Geophys. Res., 94(C8), 10,937-10,954.

Morassutti, M. P., and E. F. LeDrew (1996), Albedo and depth of melt ponds on sea-ice, Int. J. Climatol., 16, 817-838.

Notz, D., M. G. McPhee, M. G. Worster, G. A. Maykut, K. H. Schlünzen, and H. Eicken (2003), Impact of underwater-ice evolution on Arctic summer sea ice, J. Geophys. Res., 108(C7), 3223, doi:10.1029/ 2001JC001173.

Perovich, D. K. (1990), Theoretical estimates of light reflection and transmission by spatially complex and temporally varying sea ice covers, J. Geophys. Res., 95(C6), 9557-9567.

Perovich, D. K. (1996), Optical properties of sea ice, Tech. Rep. 96-1, U.S. Army Corps of Eng., Cold Reg. Res. Eng. Lab., Hanover, N. H.

Perovich, D. K., and B. Elder (2002), Estimates of ocean heat flux at SHEBA, Geophys. Res. Lett., 29(9), 1344, doi:10.1029/2001GL014171.

Perovich, D. K., G. A. Maykut, and T. C. Grenfell (1986), Optical properties of ice and snow in the polar oceans: I: Observations, Proc. SPIE Int Soc. Opt. Eng., 637, 232-241.

Perovich, D. K., T. C. Grenfell, B. Light, J. A. Richter-Menge, M. Sturm, W. B. Tucker III, H. Eicken, G. A. Maykut, and B. Elder (1999), SHEBA: Snow and ice studies, version 1.0 [CD-ROM], report, D. K. Perovich, Cold Reg. Res. Eng. Lab., Hanover, N. H.
Perovich, D. K., T. C. Grenfell, B. Light, and P. V. Hobbs (2002), Seasonal evolution of the albedo of multiyear Arctic sea ice, J. Geophys. Res., 107(C10), 8044, doi:10.1029/2000JC000438

Perovich, D. K., T. C. Grenfell, J. A. Richter-Menge, B. Light, W. B. Tucker III, and H. Eicken (2003), Thin and thinner: Ice mass balance measurements during SHEBA, J. Geophys. Res., 108(C3), 8050, doi:10.1029/2001JC001079.

Podgorny, I. A., and T. C. Grenfell (1996), Partitioning of solar energy in melt ponds from measurements of pond albedo and depth, J. Geophys. Res., 101(C10), 22,737-22,748.

Rogers, R. R., and M. K. Yau (1989), A Short Course in Cloud Physics, Pergamon, New York.

Shine, K. P., and A. Henderson-Sellers (1985), The sensitivity of a thermodynamic sea ice model to changes in surface albedo parameterization, J. Geophys. Res., 90(D1), 2243-2250.

Sturm, M. J. Holmgren, and D. K. Perovich (2002), Winter snow cover on the sea ice of the Arctic Ocean at the Surface Heat Budget of the Arctic Ocean (SHEBA): Temporal evolution and spatial variability, J. Geophys. Res., 107(C10), 8047, doi:10.1029/2000JC000400.

Taylor, P. D. (2003), Mathematical modelling the formation and evolution of melt ponds on sea ice, Ph.D. thesis, Univ. of London, London, UK.

Untersteiner, N. (1968), Natural desalination and equilibrium salinity profile of perennial sea ice, J. Geophys. Res., 73(4), 1251-1257.

Wadhams, P. (2000), Ice in the Ocean, Gordon and Breach, Newark, N. J.

Weeks, W. F., and S. F. Ackley (1986), The growth, structure and properties of sea ice, in The Geophysics of Sea Ice, NATO ASI Ser. B, Physics, vol. 146, edited by N. Untersteiner, pp. 9-164, Plenum, New York.

Wettlaufer, J. S., M. G. Worster, and H. E. Huppert (1997), The phase evolution of young sea ice, Geophys. Res. Lett., 24, 1251-1254.

Wettlaufer, J. S., M. G. Worster, and H. E. Huppert (2000), Solidification of leads: Theory, experiment, and field observations, J. Geophys. Res., 105(C1), 1123-1134.

Wiscombe, W. J., and S. G. Warren (1980), A model for the spectral albedo of snow, J. Atmos. Sci., 37, 2712-2733.

D. L. Feltham and P. D. Taylor, Centre for Polar Observation and Modelling, Department of Space and Climate Physics, University College London, Gower Street, London WC1E 6BT, UK. (dlf@cpom.ucl.ac.uk; pdt@cpom.ucl.ac.uk) 